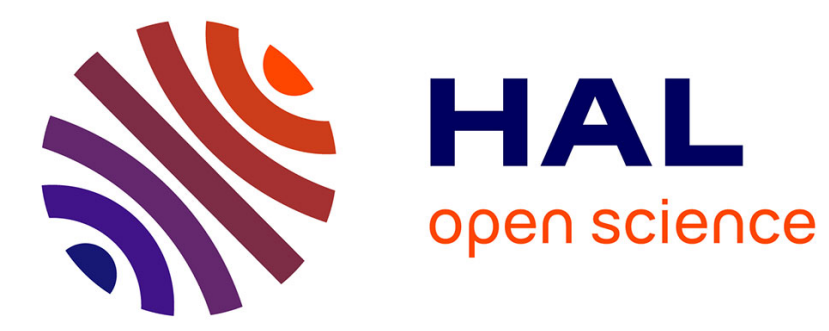

\title{
EFFECT OF THE FREQUENCY OF INTRAMOLECULAR MOTIONS ON THE NMR RELAXATION IN LIQUID STATE TEMPERATURE REGIME
}

Lidia Latanowicz, Zofia Gdaniec

\section{To cite this version:}

Lidia Latanowicz, Zofia Gdaniec. EFFECT OF THE FREQUENCY OF INTRAMOLECULAR MOTIONS ON THE NMR RELAXATION IN LIQUID STATE TEMPERATURE REGIME. Molecular Physics, 2009, 107 (15), pp.1563-1576. 10.1080/00268970902980045 . hal-00513295

\section{HAL Id: hal-00513295 \\ https://hal.science/hal-00513295}

Submitted on 1 Sep 2010

HAL is a multi-disciplinary open access archive for the deposit and dissemination of scientific research documents, whether they are published or not. The documents may come from teaching and research institutions in France or abroad, or from public or private research centers.
L'archive ouverte pluridisciplinaire HAL, est destinée au dépôt et à la diffusion de documents scientifiques de niveau recherche, publiés ou non, émanant des établissements d'enseignement et de recherche français ou étrangers, des laboratoires publics ou privés. 


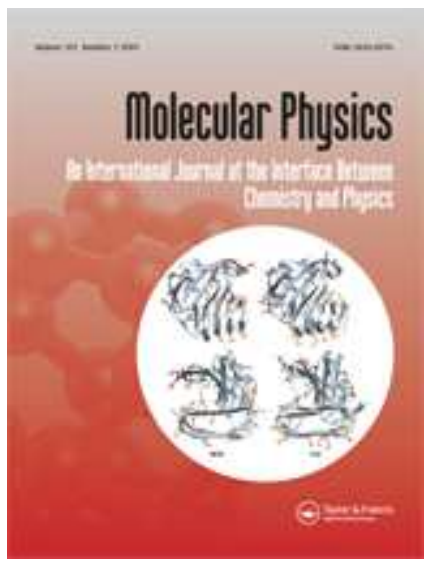

\section{EFFECT OF THE FREQUENCY OF INTRAMOLECULAR MOTIONS ON THE NMR RELAXATION IN LIQUID STATE TEMPERATURE REGIME}

\begin{tabular}{|r|l|}
\hline Journal: & Molecular Physics \\
\hline Manuscript ID: & TMPH-2009-0021.R1 \\
\hline Manuscript Type: & Full Paper \\
\hline Date Submitted by the \\
Author: & 27-Feb-2009 \\
\hline Keywlete List of Authors: & $\begin{array}{l}\text { Latanowicz, Lidia; University of Zielona Góra, Faculty of Biological } \\
\text { Sciences } \\
\text { Gdaniec, Zofia; Polish Academy of Sciences, Institute of Bioorganic } \\
\text { Chemistry }\end{array}$ \\
\hline & $\begin{array}{l}\text { complex molecular motion, spectral densities, internal motions, } \\
\text { Nonamics of mono-saccharide in solution, 13C T1 NMR relaxation, } \\
\text { NOEs-relaxation rate }\end{array}$ \\
\hline
\end{tabular}

\section{今 scholarONE" \\ Manuscript Central}




\title{
EFFECT OF THE FREQUENCY OF INTRAMOLECULAR MOTIONS ON THE NMR RELAXATION IN LIQUID STATE TEMPERATURE \\ REGIME
}

\author{
L. Latanowicz ${ }^{\mathrm{a}}$, Z. Gdaniec ${ }^{\mathrm{b}}$ \\ ${ }^{a}$ Faculty of Biological Sciences, University of Zielona Góra, Szafrana 1, 65-516 Zielona \\ Góra, Poland \\ ${ }^{b}$ Institute of Bioorganic Chemistry, Polish Academy of Sciences, Noskowskiego 12/14, 61 - \\ 704 Poznań, Poland
}

Corresponding author: L. Latanowicz, jlat@amu.edu.pl

\begin{abstract}
Key words : Spectral densities of complex molecular motion, activation parameters of the internal motions, interatomic distances, "model - free approach", ${ }^{13} \mathrm{C} \mathrm{T}_{1} \mathrm{NMR}$ relaxation, NOE cross-relaxation rate, dynamics of mono-saccharide in solution.
\end{abstract}




\begin{abstract}
Equations for the spectral densities of complex motion of a spin pair undergoing internal motion and isotropic/anisotropic overall rotation have been considered. The fluctuations of the interproton distances, caused by internal motion, have been taken into account in the theoretical equations. A method allowing a distinction between the isotropic and the anisotropic overall rotation of molecules has been proposed.

The effect of the activation parameters of internal motions (known from the solid state study) on the measured $T_{1}$ relaxation of the ${ }^{13} \mathrm{C}$ and ${ }^{1} \mathrm{H}-{ }^{1} \mathrm{H}$ cross-relaxation rates has been analysed for methyl- $\beta$-D-galactopyranoside in DMSO-d6 solution. The conformational transgauche jumps of the methylene group are not fast enough to affect the $T_{1}$ value of carbon C6 in the liquid state temperatures regime. Only the methyl group rotation is a very fast internal motion. This motion influences the carbon $\mathrm{C} 7$ relaxation and methyl protons - anomeric proton cross - relaxation. The values of interatomic distances between anomeric $\mathrm{H}(\mathrm{C} 1)$ and $\mathrm{H}(\mathrm{C} 5)$ as well as the three methyl protons $\mathrm{H}(\mathrm{C} 7)$ have been calculated from the crossrelaxation rates. The distance $\mathrm{H}(\mathrm{C} 1)-\mathrm{H}(\mathrm{C} 7)$ fluctuates due to the rotation of methyl group. The application of the "model - free approach" to study molecular dynamics in solutions is discussed.
\end{abstract}




\section{Introduction}

The spin-lattice relaxation times are sensitive to stochastic molecular motions.

Usually, interpretation of the experimentally determined temperature dependence of the ${ }^{13} \mathrm{C}$ spin-lattice relaxation time permits identification of interatomic distances, activation energies and correlation times. Analysis of homo- and hetero-nuclear cross-relaxation rates has been widely used to derive the inter-atomic distances and motional parameters of small molecules and biological macromolecules [1-11].

The stochastic molecular motions can be of diffusion or hindered rotation character (hopping among potential minima corresponding to separate equilibrium sites). The first model of the hindered rotations was proposed by Debye [12] to explain the phenomenon of dielectric relaxation. This model was developed further by Hoffman [13, 14]. The hopping among equilibrium sites occurs when a molecular group jumps between trans and gauche conformations, when a molecule has internal flexibility (butterfly-like motion or ring puckering), when a proton is transferred between two positions in a hydrogen bond or when a hindered rotation of a molecular group (or side chains in macromolecules) takes place in a symmetrical or asymmetrical local environment.

In liquid state, the molecular motion is complex. The motion of molecular groups accompanies the overall rotational tumbling of the molecule. The complex motion of a spin pair belonging to a methyl group jumping between three equivalent potential minima and subjected to isotropic rotational diffusion was first considered by Woessner [15 - 17] and next by Wallach [18] and also by Dellwo and Wand [19]. That the $T_{1}$ relaxation time minimum corresponding to the slowest component motion is shallower than the minimum $T_{1}$ associated with such a motion in the absence of the faster motions has been shown in papers $[15,16,18$ 22]. 
The internal motion can lead to fluctuations of internuclear distances. Relaxation rates are sensitive to the changes in the spin-spin vector, $\boldsymbol{R}_{\boldsymbol{i s}}$, orientation and length. The expressions derived in [20-27] are applicable to study simultaneous changes in orientation and magnitude of $R_{i s}$ in the internal molecular motions. The effect of fluctuating internuclear distances in non-rigid molecules on nuclear magnetic relaxation was also considered by Tropp [28].

The complex motion of $\boldsymbol{R}_{i s}$ vector $\left(R_{i s}=\right.$ const $)$ consisting of overall isotropic tumbling and jumping among equilibrium sites (internal motion) has been generalized in the "model-free approach" proposed by Lipari and Szabo [29, 30]. The activation parameters of internal motions are not taken into account in the "model-free approach". The isotropic tumbling is assumed to be sufficiently slower than the internal motion. The influence of the internal motions on the spectral density and therefore, on the spin - lattice relaxation rate in liquids is expressed by the "order parameter" $S^{2}$. The application of the "model - free approach" to study molecular dynamics in solutions is discussed in our paper.

In the present paper the methods of ${ }^{13} \mathrm{C} T_{1}$ NMR relaxation and ${ }^{1} \mathrm{H}-{ }^{1} \mathrm{H}$ crossrelaxation rate (NOE) have been applied to study the overall and internal molecular dynamics and also the internuclear distances in the methyl- $\beta$-D-galactoside molecule in DMSO - $\mathrm{d} 6$ solution. Different models of the spectral densities of the complex motion are discussed. It will be shown that the assumptions of the internal motion being faster than the overall motion and the internuclear distance taking a constant value during the internal motion significantly restrict the applications of the "model-free approach" in our study. 


\section{Theory}

\subsection{Longitudinal and cross relaxation rates}

Longitudinal relaxation, $T_{1}$, involves the energy exchange events between the nuclear states and the lattice. The relaxation of the spin pair "is" can occur across six transitions; the four single quantum transitions, $W_{1}^{i s}$, involving a spin flip of only one of the two spins (either "i" or "s"), the double quantum, $W_{2}^{\text {is }}$, involving a simultaneous spin flip of both spins in the same direction, and $W_{0}^{\text {is }}$ transition involving a simultaneous spin flip in the opposite sense. Only dipolar coupling between " $i$ " and "s" will cause double- and zero quantum transitions, $W_{0}^{\text {is }}$ and $W_{2}^{\text {is }}$, and these will lead to NOE enhancement. For these $W_{2}^{\text {is }}$ transitions to occur, the local field resulting from lattice motions must contain fluctuations at the sum of the resonance frequencies $\left(\omega_{i}+\omega_{s}\right)$. For $W_{0}^{i s}$ transitions the local field must contain fluctuations at the difference frequency $\left(\omega_{i}-\omega_{s}\right)$.

The $W_{m}$ probabilities of transitions where $m=0,1,2$ are proportional to the spectral density functions $\left(W_{m}^{i s} \propto J_{i s}^{m}(\omega)\right)$. The spectral densities of the spin pair "is", $J_{i s}^{m}(\omega)$ are Fourier transforms of the dipolar correlation functions $\left\langle F_{i s}^{m}(t) F_{i s}^{m *}(t+T)\right\rangle$ and carry information on the reorientation of the is distance vector $R_{i s}$ :

$$
J_{i s}^{m}(\omega)=\int_{-\infty}^{+\infty}\left\langle F_{i s}^{m}(t) F_{i s}^{m *}(t+\tau)\right\rangle \exp (-i \omega \tau) d \tau
$$


The random functions of time in the dipolar interaction hamiltonian, $F_{i s}{ }^{m}(t)$ for a given nuclear spin pair is are:

$$
\begin{aligned}
& F_{\text {is }}^{0}(t)=d_{\text {is }}(t)\left[3 \cos ^{2} \vartheta_{i s}(t)-1\right] \\
& F_{\text {is }}^{ \pm 1}(t)=d_{\text {is }}(t) \sin \vartheta_{\text {is }}(t) \cos \vartheta_{\text {is }}(t) \exp \left( \pm i \varphi_{\text {is }}(t)\right) \\
& F_{\text {is }}^{ \pm 2}(t)=d_{\text {is }}(t) \sin ^{2} \vartheta_{\text {is }}(t) \exp \left( \pm i 2 \varphi_{\text {is }}(t)\right)
\end{aligned}
$$

where $d_{i s}(t)=\left(\mu_{0} / 4 \pi\right) \gamma_{i} \gamma_{s} \hbar R_{l s}^{-3}(t)$ is the dipolar coupling constant, $\mu_{o}$ is the permittivity of free space, $R_{i s}$ is the distance between the spins (i) and $(s), \vartheta_{i s}$ and $\varphi_{i s}$ are the polar and azimuth angles, respectively, describing the orientation of the internuclear vector in the laboratory frame with the $\boldsymbol{Z}$ axis in the direction of the external magnetic field $\boldsymbol{B}_{0}, \gamma_{l}$ and $\gamma_{s}$ are the gyromagnetic ratios. Thermal motion in a physical system makes the values of $\vartheta_{\text {is }}$ and $\varphi_{\text {is }}$ time dependent. The length of the $\boldsymbol{R}_{\text {is }}$ vector can be time dependent also when only one proton undergoes internal reorientation. The NMR relaxation of protonated carbons is usually caused by dipole - dipole interaction with the directly bonded proton spins. The experiments are performed with simultaneous proton irradiation (continuous-wave proton decoupling) and the longitudinal relaxation rate of each is spin pair is equals $\frac{1}{T_{1}^{i s}}=W_{0}+2 W_{1}+W_{2}$, and therefore [31]:

$$
\frac{1}{T_{1}^{i s}}=\frac{3}{4}\left[\frac{1}{12} J_{i s}^{0}\left(\omega_{i}-\omega_{s}\right)+\frac{3}{2} J_{i s}^{1}\left(\omega_{i}\right)+\frac{3}{4} J_{i s}^{2}\left(\omega_{i}+\omega_{s}\right)\right]
$$


where $\omega_{i}$ and $\omega_{s}$ are the angular resonance frequencies of " $i$ " and "s" spins.

The maximum of the steady-state NOE enhancement, $\eta$, is given by the ratio of the cross- relaxation rate to the total, $\left(1 / T_{1}^{i s}\right)$, relaxation rates.

$$
\eta=\frac{\gamma_{S}}{\gamma_{I}} \frac{\sigma_{N O E}^{i s}}{\left(1 / T_{1}^{i s}\right)}
$$

The maximum theoretical value of $\eta$, represents the NOE enhancement expected at " $i$ " on saturation of "s". The maximum $\eta$ will only be reached if the dipolar interaction is dominant and the other processes negligible (problem I >1/2, paramagnetic impurities like oxygen).

The cross-relaxation rate, $\left(\sigma_{N O E}^{i s}\right)$, controls the rate of the NOE enhancement transfer between " $i$ " and "s". The NOE effect needs time to build up when the population of a nearby proton is changed by saturation or by its population inversion with a $180^{\circ}$ pulse (transient NOE). The definition of $\sigma_{N O E}^{\text {is }}$ is $\sigma_{N O E}^{\text {is }}=w_{2}-w_{0}$. Thus the cross-relaxation rate of a pair of non-equivalent spins " $i$ " and " $s$ ", separated by $R_{i s}$, in laboratory-frame, $\sigma_{N O E}^{i s}$, is related to the following spectral densities $[1,4,6,11]$.

$$
\sigma_{N O E}^{i s}=\frac{1}{16}\left[9 J_{i s}^{2}\left(\omega_{i}+\omega_{s}\right)-J_{i s}^{0}\left(\omega_{i}-\omega_{s}\right)\right]
$$

The values of $T_{1}^{i s}$ can be obtained from the experimental values of $T_{1}$, of a given carbon, directly bonded to $N$ protons according to the equation 


$$
T_{1}^{i s}=N T_{1}
$$

For proton $i$ directly interacting with $(N-1)$ protons $s$, as for example the ring proton and the three methyl protons, the value of the measured cross relaxation rate $\sigma_{N O E}$ is a sum of the cross relaxation rates given in Equation (7).

$$
\sigma_{N O E}=\sum_{i=1}^{1} \sum_{s=2}^{N} \sigma_{N O E}^{i s}
$$

\subsection{Spectral densities for different models of stochastic molecular motions}

\subsubsection{Single-axial hindered rotation $\left(C_{n}\right)$}

The majority of the internal motions can be considered as jumps between three or two equilibrium sites. The values of the potential energy minima at separate equilibrium sites are the same in this model. The general equations for single axial motions take into account the simultaneous changes in the orientation and length of the $\boldsymbol{R}_{\boldsymbol{i s}}$ vector in the motion [20 - 28]. The correlation functions and spectral densities of hopping among two $(n=2) \mathrm{A}$ and $\mathrm{B}$ or three $(n=3) \mathrm{A}, \mathrm{B}$ and $\mathrm{C}$ equivalent equilibrium sites are

$$
\left\langle F_{i s}^{m}(t) F_{i s}^{m *}(t+\tau)\right\rangle=S_{n}^{m}+\left(S_{n}^{r m}-S_{n}^{m}\right) \exp \left(-\frac{|T|}{T_{n}}\right)
$$

and 


$$
J_{i s}^{m}(\omega)=\left(S_{n}^{r m}-S_{n}^{m}\right) \frac{2 T_{n}}{1+\omega^{2} T_{n}{ }^{2}}+\delta S_{n}^{m}
$$

where the correlation time $\tau_{n}$ of given reorientation follows the Arrhenius temperature dependence

$$
I_{n}=\tau_{0}^{n} \exp \left(\frac{E_{n}}{R T}\right)
$$

and $r_{0}^{n}$ and $E_{n}$ are the preexponential factor and the activation energy.

The correlation function (Equation 10) does not vanish in infinity but converges to a non zero constant. Therefore, its Fourier transform is divergent, unless the distribution theory is invoked - then the Fourier transform of a constant is Dirac's delta function.

The most general theoretical equations for the coefficients $s_{n}^{m}$ and $s_{n}^{r m}$ due to the hopping of $R_{\text {is }}$ between two (twofold hindered rotation) and three (threefold hindered rotation) equilibrium sites are given in references [20 - 28]. These, for powdered solids or liquids, are

$$
S_{2}^{r m}=\frac{<\left[F_{i s}^{m}(A)\right]^{2}>+<\left[F_{i s}^{m}(B)\right]^{2}>}{2},
$$

$$
S_{3}^{r m}=\frac{<\left[F_{i s}^{m}(A)\right]^{2}>+<\left[F_{i s}^{m}(B)\right]^{2}>+<\left[F_{i s}^{m}(C)\right]^{2}>}{3},
$$

$$
S_{2}^{m}=\frac{1}{4}\left\langle\left[F_{i s}^{m}(A)+F_{i s}^{m}(B)\right]^{2}\right\rangle,
$$




$$
S_{3}^{m}=\frac{1}{9}\left\langle\left[F_{i s}^{m}(A)+F_{i s}^{m}(B)+F_{i s}^{m}(C)\right]^{2}\right\rangle
$$

where $F_{i s}^{m}(A), F_{i s}^{m}(B), F_{i s}^{m}(C)$ are the values of the random functions (Equations $2-4$ ) at the A, $\mathrm{B}$ or $\mathrm{C}$ sites.

The following isotropic ensemble averages (powdered solids or liquids) of the random function products are necessary for further calculations of spectral densities:

$$
\left\langle F_{i s}^{m}(X) F_{i s}^{m}(Y)\right\rangle=K^{m} d_{i s}(X) d_{i s}(Y) P_{2}\left(\cos \left(\Theta_{X Y}^{i s}\right)\right)
$$

where $\mathrm{X}=\mathrm{A}, \mathrm{B}, \mathrm{C}, \mathrm{Y}=\mathrm{A}, \mathrm{B}, \mathrm{C}, K^{m}$ equals $4 / 5,2 / 15,8 / 15$ for $m=0,1,2$ respectively, $d_{i s}(X)=\left(\mu_{0} / 4 \pi\right) \gamma_{i} \gamma_{s} \hbar R_{l s}^{-3}(X), d_{i s}(Y)=\left(\mu_{0} / 4 \pi\right) \gamma_{i} \gamma_{s} \hbar R_{l s}^{-3}(Y), P_{2}\left(\cos \Theta_{X Y}^{i s}\right)=\frac{1}{2}\left(3 \cos ^{2} \Theta_{X Y}^{i s}-1\right)$ denotes the Legendre polynomial, $\Theta_{X Y}^{i s}$ is the angle between the $\boldsymbol{R}_{\boldsymbol{i s}}$ vectors at the separate equilibrium sites.

On substituting the isotropic ensemble averages (Equation (17)) into Equations (1316) we find the following coefficients $s_{n}^{m}$ and $s_{n}^{r m}$ :

$$
\begin{aligned}
& S_{n}^{r m}=K^{m} D_{i s}^{2}, \\
& S_{n}^{m}=K^{m} S_{n},
\end{aligned}
$$

where 


$$
D_{i s}^{2}=\frac{1}{n} \sum_{X} d_{i s}(X)^{2}
$$

and

$$
S_{n}=\frac{1}{n^{2}} \sum_{X} \sum_{Y} d_{i s}(X) d_{i s}(Y) P_{2}\left(\cos \left(\Theta_{X Y}\right)\right)
$$

The $D_{i s}{ }^{2}$ is the root mean square of the dipolar coupling constants $d_{i s}(X)$ and

$$
S_{2}=\frac{1}{4}\left[d_{i s}(A)^{2}+d_{i s}(B)^{2}+d_{i s}(A) d_{i s}(B)\left(3 \cos ^{2} \Theta_{2}^{i s}-1\right)\right]
$$

or

$$
\begin{aligned}
& S_{3}=\frac{1}{9}\left[d_{i s}(A)^{2}+d_{i s}(B)^{2}+d_{i s}(C)^{2}+d_{i s}(A) d_{i s}(B)\left(3 \cos ^{2} \Theta_{A B}^{i s}-1\right)\right]+ \\
& \left.\left.d_{i s}(A) d_{i s}(C)\left(3 \cos ^{2} \Theta_{A C}^{i s}-1\right)\right]+d_{i s}(B) d_{i s}(C)\left(3 \cos ^{2} \Theta_{B C}^{i s}-1\right)\right]
\end{aligned}
$$

The single-axial rotation can be also of diffusion (small angle jumps) character [1517]. The differences in the temperature dependencies of spectral densities of both types of single-axial motions - diffusional and hindered, $C_{3}$, for the same motion parameters are very small. Therefore, Equation (23) can be applied generally for single axial rotation of $\boldsymbol{R}_{\text {is }}$ vector.

2.2.2 Complex motion $\left(C_{i s o}+C_{n}\right)$ 
Molecules in liquids undergo a complex motion; i. e. the overall motion accompanies the internal motions. The equation for the spectral densities of the complex motion consisting of hopping among two or three equivalent equilibrium sites and isotropic tumbling of molecule, $\left(C_{i s o}+C_{n}\right)$, is presented in papers [15, 16, 22, 25, $\left.27-30\right]$.

$J_{i j}^{m}(\omega)=K^{m} D_{i s}{ }^{2}\left[S^{2} \frac{2 T_{i s o}}{1+\omega^{2} T_{\text {iso }}{ }^{2}}+\left(1-S^{2}\right) \frac{2 T_{\text {ison }}}{1+\omega^{2}{ }_{\text {ison }}{ }^{2}}\right]$

where

$s^{2}=\frac{s_{n}}{D_{i s}^{2}}$

and

$$
\frac{1}{T_{\text {ison }}}=\frac{1}{T_{\text {iso }}}+\frac{1}{T_{n}}
$$

Thus, for $d_{i s}(A)=d_{i s}(B)=d_{i s}(C)$ and $\Theta_{A B}^{i s}=\Theta_{A C}^{i s}=\Theta_{B C}^{i s}=\Theta_{3}^{i s}$, according to Equations 25, 22 and $23, s^{2}=\left(1-\frac{3}{4} \sin ^{2} \Theta_{2}^{i s}\right)$ (two site jumps) or $s^{2}=\cos ^{2} \Theta_{3}^{i s}$ (hindered rotation). Therefore, the values of $S^{2}$ are in the range $0<S^{2}<1$ as shown in Fig. 1

This parameter $S^{2}$ has been called by Lipari and Szabo [29, 30] the order parameter.

The temperature dependence of the correlation time follows the Arrhenius dependence

$T_{\text {iso }}=T_{0}^{\text {iso }} \exp \left(\frac{E_{\text {iso }}}{R T}\right)$ 
where, $r_{0}^{i s o}$ and $E_{i s o}$ are the preexponential factor and the activation energy.

When $\tau_{n} \rightarrow \infty$ (no internal motion) and also $\tau_{\text {iso }}<\tau_{n}$ (slow internal motion), Equation (24) is reduced to the expression

$$
J_{i j}^{m}(\omega)=K^{m} D_{\text {is }}{ }^{2} \frac{2 T_{\text {iso }}}{1+\omega^{2} \text { iso }_{\text {iso }} 2}
$$

When $\left.d_{i s}(A)=d_{i s}(B)=d_{i s}(C)\right)$ then $D_{i s}{ }^{2}=d_{i s}{ }^{2}$ Equation (28) is the well-known BPP expression for isotropic motion [32]. Thus the slow internal motion, $\left(\tau_{\text {iso }}<\tau_{n}\right)$, has no influence on the value of the spectral density of complex motion in the high temperature regime.

Equation (24) is reduced to a simpler form when $\tau_{\text {iso }}>>\tau_{n}$ (internal motion is much faster than isotropic overall tumbling):

$$
J_{i s}^{m}(\omega)=K^{m}{ }_{i s}{ }^{2} S^{2} \frac{{ }^{2 T_{i s o}}}{1+\omega^{2} T_{\text {iso }}{ }^{2}}
$$

The spectral density given in Equation (29) is reduced in comparison to this given in Equation (28) when $S^{2}<1$. Therefore the $T_{1}$ relaxation time minimum corresponding to the slower motion is made shallower by faster motions and does not reflect the minimum associated with such a motion in the absence of faster motions. Thus each internal reorientation, which is much faster than overall reorientation, contributes a single factor given by Equation (25) to 
the relaxation rate at temperatures at which the function $\frac{2{ }^{2} \text { iso }}{1+\omega^{2} \tau_{\text {iso }} 2}$ reaches a maximum.

Similar conclusions were made in papers 18, 19, 22, 25, 29, 30.

The spectral density given in Equation (29) depends on the product of squares of the dipolar coupling constant and the order parameter, $\left(D_{i s}{ }^{2} S^{2}\right)$. Therefore, $J_{i s}^{m}(\omega)$ is not only sensitive to the order parameter $S^{2}$, but also to the value of $R_{i s}{ }^{-6}$. For instance, when $S=1$, the difference $\Delta R_{i s}$ of $2 \%$ corresponds to the difference in the value of $J_{i s}^{m}(\omega)$ of about $11 \%$.

The dependence of the spectral density on the product $D_{i s}{ }^{2} S^{2}$ is the reason for the problems in distinguishing between changes in the relaxation rates appearing in response to the changes in $D_{i s}$ or $S^{2}$ separately.

\subsubsection{Complex motion $\left(C_{\text {aniso }}+C_{n}\right)$}

The anisotropy of the rotational diffusion tensor can be full with the principal values $D_{x x} \neq D_{y y} \neq D_{z z}$ or can be treated as a motion of a symmetrical top (oblate or prolonged) with $D_{x x}=D_{y y} \neq D_{z z}$. A model describing the motion of a rigid molecule of an arbitrary shape has been developed by Woessner [16], Huntress [33] and Hubbard [34] and Canet [35] ${ }^{1}$. This motion of rigid molecules about a threefold axis can be described by the inertial tensor for the gas phase and by the rotational diffusion tensor for the liquid state. Levy et al. [38] assumed that the principal axis system of the rotational diffusion tensor was coincident with that of the inertial tensor. That the diffusion and inertia axes almost coincide and simultaneously, the

\footnotetext{
${ }^{1}$ The spectral density due to the complex motion which is a combination of the fully anisotropic overall molecular tumbling with the internal motion has been recently published in [36, 37]. The formulas obtained in these papers (Equation (15) in the reference 36) seem to be incorrect, because the authors have neglected the space averaging of the products of the random functions. They wrote $\left\langle F_{i s}^{m}(X) F_{i s}^{m}(Y)\right\rangle=K^{m} d_{i s}(X) d_{i s}(Y)$, while it should be $\left\langle F_{i s}^{m}(X) F_{i s}^{m}(Y)\right\rangle=K^{m} d_{i s}(X) d_{i s}(Y) P_{2}\left(\cos \left(\Theta_{x y}\right)\right.$.
} 
sequence of the diffusion coefficients is opposite to the sequence of the moment of inertia was found for 9-methylpurine in $\mathrm{CD}_{3} \mathrm{OD}$ solutions [39].

The expression for the spectral density of anisotropic overall motion of a symmetric top molecule has been derived by Woessner [16]. The spectral density of the complex motion $\left(C_{\text {aniso }}+C_{n}\right)$ consisting of anisotropic (type symmetrical top) overall motion, $C_{\text {aniso, }}$ and internal motion $C_{n}$, where $n=2$ or $n=3$ marks jumps among three or two sites of equal energy, can be easily derived in the same way as the spectral density of $\left(C_{i s o}+C_{n}\right)$ (Equation (24)):

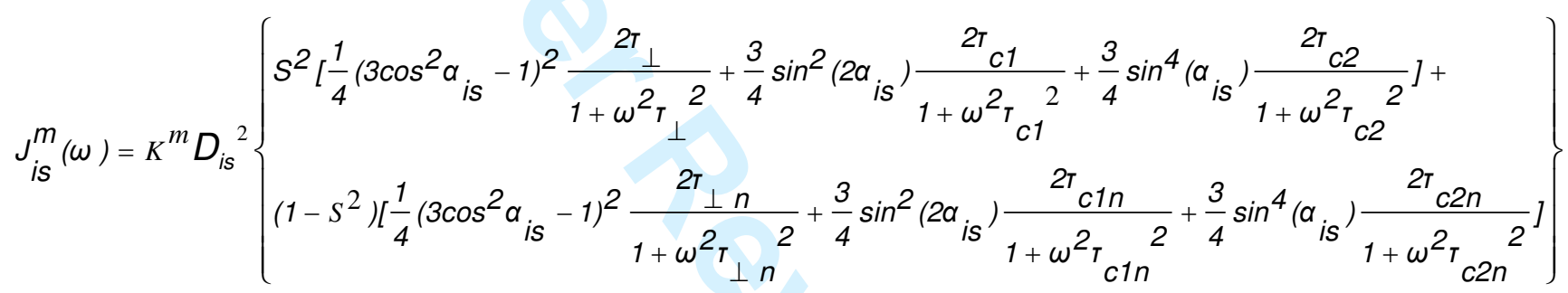

where

$$
\frac{1}{{ }^{T_{\perp n}}}=\frac{1}{{ }^{T_{C \perp}}}+\frac{1}{T_{n}}
$$

$$
\frac{1}{{ }^{T_{C 1 n}}}=\frac{1}{{ }^{T_{C 1}}}+\frac{1}{T_{n}}
$$

$$
\frac{1}{{ }^{T_{C 2 n}}}=\frac{1}{{ }^{T_{C 2}}}+\frac{1}{{ }^{T_{n}}}
$$




$$
\begin{aligned}
& \frac{1}{{ }^{T_{\perp}}}=6 D_{\perp} \\
& \frac{1}{{ }^{{ } C 1}}=5 D_{\perp}+D_{\|} \\
& \text {and } \\
& \frac{1}{{ }^{T} c 2}=4 D_{\perp}+2 D_{\|}
\end{aligned}
$$

$\alpha_{i s}$ is the angle between the $\boldsymbol{R}_{i s}$ and the symmetry axis of the molecule. The main values of the rotational diffusion tensor (coefficients of rotational diffusion) $D_{x x}=D_{y y}=D_{\perp}$ and $D_{z z}=$ $D_{/ /}$follow the Arrhenius temperature dependence:

$$
\begin{aligned}
& D_{\|}=D_{0}^{\prime \prime} \exp \left(-\frac{E_{I I}}{R T}\right) \\
& D_{\perp}=D_{0}^{\perp} \exp \left(-\frac{E_{\perp}}{R T}\right)
\end{aligned}
$$

where $D_{0}^{\prime \prime}$ and $D_{0}^{\perp}$ are preexponential factors, $E_{/ /}$and $E_{\perp}$ are activation energies.

\subsubsection{The model free - approach}


The Lipari and Szabo model considers the spectral densities of a complex motion $\left(C_{\text {iso }}\right.$ $+C_{n}$ ) for $R_{i s}=$ const. This model, known as the "model - free approach", is often applied to estimate the jump angles of the internal motions. Lipari and Szabo have proposed to assume the "free" values of $S^{2}$ in the range $0.25<S^{2}<1$. The value $S^{2}=1$ means that the $R_{i s}$ vector is not involved in internal motion. It is believed that the lower from 1 the value of $S^{2}$ the greater the jump angles $\Theta_{2}^{i s}$ or $\Theta_{3}^{i s}$ (Equations (22) and (23)) it characterises. All internal motions considered are assumed to be much faster than the overall tumbling $\left(\tau_{n}<<\tau_{\text {iso }}\right)$. The model - free approach does not take into account the activation parameters of internal molecular motions and changes of the internuclear distances, $R_{i s}$.

The order parameter, under assumption of the fast internal motion, can be obtained from the ratio of spectral densities given in Equations 28 and 29, that is :

$$
S^{2}=\frac{(\text { equation 29) }}{\text { (equation 28) }}
$$

If the correlation time of internal motion $\tau_{n}$ is known, the same procedure of estimation of the order parameter can be applied by using full Equation 24 for the spectral density of the complex motion, that is

$$
S^{2}=\frac{(\text { equation } 24)}{\text { (equation } 28)}
$$

Figure 2 presents $S^{2}$ as a function of the ratio $\tau_{\text {iso }} / \tau_{n}$ obtained with the help of Equation (40) The internal motion is assumed to be jumps in triple potential (Equation $25, R_{i s}=$ const, $\left.s^{2}=\cos ^{2} \Theta_{3}^{i s}\right)$. Therefore Equation 40 gets the form: 


$$
S^{2}=\frac{\cos ^{2} \Theta_{3}^{i s} \frac{{ }^{2 \tau}{ }_{\text {iso }}}{1+\omega^{2} \tau_{\text {iso }}{ }^{2}}+\sin ^{2} \Theta^{i s} \frac{{ }^{2 \tau} \text { ison }}{1+\omega^{2} \tau_{\text {ison }}{ }^{2}}}{\frac{{ }^{2 \tau}{ }_{\text {iso }}}{1+\omega^{2} \tau_{\text {iso }}{ }^{2}}}
$$

The question is what should be the difference between the correlation times of the internal and isotropic overall motion of the molecule in order to obtain the true value of $S^{2}$. As shown in Figure $2, S^{2}$ reaches the value $\cos ^{2}\left(0.109 .4^{\circ}\right)=0.11$ for the ratio $\tau_{\text {iso }} / \tau_{n} \geq 40$. Such a great difference between $\tau_{n}$ and $\tau_{\text {iso }}$ can be expected for the $\tau_{n}$ representing hindered rotations of the $\mathrm{CH}_{3}$ group of methyl- $\beta$ D galactopyranoside. The conclusion following from Equations (39) and (40) is that slow internal motion in comparison to overall motion does not affect the value of $T_{1}^{i s}$ in the temperature range corresponding to the liquid phase. $S^{2}=\frac{S_{n}}{D_{i s}{ }^{2}}$ only for a fast internal motion $\left(\tau_{n} \ll \tau_{\text {iso }}\right)$. The condition $\tau^{\text {int }} \ll \tau^{\text {iso }}$ is also expected for macromolecules such as proteins in solution. The protein overall correlation time is in the range of nanoseconds, while the internal motion correlation times are in the range of picoseconds $[40-42]$.

The interatomic distances are in the sixth power in the relaxation equations; therefore, the differences in the chemical C-H bond length can give serious differences in the values of $T_{1}$. It seems that in the majority of situations described in literature, the "model - free approach" was applied to small molecules and the $S^{2}$ values were obtained in the range $0.75<$ $S^{2}<1$, the differences in $S^{2}$ originated from the differences in $R_{i s}$ (the lengths of the C-H bond).

The "model free-approach" of spectral density cannot be also applied to study the protonproton cross-relaxation rate, $\sigma_{\text {NOE }}^{\text {is }}$ because the assumption $R_{i s}=$ const can involve significant 


\subsection{The effect of internal motion on the spin lattice relaxation in the liquid state temperature regime.}

The spectral density of a single motion which is $C_{i s o}$ (Equation (28)) or $C_{n}$ (Equation (11)) goes through a maximum in the temperature dependence. Therefore ${ }^{13} C T_{1}$ goes through a minimum (Equation 5). The minimum due to faster motion appears at lower temperatures then the minimum of a slower motion. Figure 3 presents the exemplary theoretical dependencies of $T_{1}^{i s}$ versus $1000 / T$ (Equations (5) and (24)) for the [ $\left.C_{i s o}+C_{3}\right]$ complex motion. The relaxation time minimum corresponding to the slower motion, $C_{\text {iso }}$ is made shallower by the faster motion, $C_{3}$, and does not reflect the minimum associated with such a motion in the absence of the faster motion. The line \#5 corresponds to $\tau_{0}^{3}=\infty$ so to the absence of the $C_{3}$ motion. The plot \#4 represents the case of the internal motion $C_{3}$ slow in comparison to the isotropic motion $C_{\text {iso. }}$. The lines \#5 and \#4 overlap, which means that the $C_{3}$ motion, characterized by the correlation time $\tau_{3}\left(\tau_{0}^{3}=4 \times 10^{-13} \mathrm{~s}, E_{3}=20 \mathrm{~kJ} / \mathrm{mol}\right)$, has no effect on the value of $T_{1}^{i s}$ in the temperature regime covering the maximum of the function $\frac{2 T_{\text {iso }}}{1+\omega^{2}{ }_{\text {iso }} 2}\left(\tau_{0}^{i s o}=1.6 \times 10^{-14} \mathrm{~s}, E_{\text {iso }}=20.5 \mathrm{~kJ} / \mathrm{mol}\right)$.

The shallowest high temperature minimum of $T_{1}^{i s}$ is obtained for the complex motion, whose $C_{3}$ motion is characterized by the correlation time $\tau_{3}\left(\tau_{0}^{3}=4 \times 10^{-13} \mathrm{~s}, E_{3}=2.5 \mathrm{~kJ} / \mathrm{mol}\right)$ (\#1). Plot \#1 represents the very fast internal motion $C_{3}$. Thus, the internal motion has to be very fast in comparison to the overall motion, $\left(\tau_{n}<<\tau_{\text {iso }}\right)$, to meet Equation (29). Therefore, 
special attention has to be paid to the relation between $\tau_{n}$ and $\tau_{\text {iso }}$. When the motional parameters of internal motion are not known, the estimated order parameter $S^{2}$ (Equation 39) can be false. Figure 3 confirms the information obtained from Figure 2

\subsection{Carbon - proton distances}

Equation 29 permits a very sensitive determination of the internuclear distance. A relative calibration can be achieved by comparing the $T_{1}^{i s}$ or $\sigma_{N O E}^{i s}$ corresponding to the unknown distance, $R_{i s}$, with that for a pair of spins of the known internuclear separation $R_{\text {ref }}$ :

$$
\frac{\left[D_{i s}\left(R_{i s}\right) S\left(R_{i s}\right)\right]^{2}}{\left[D_{i s}\left(R_{\text {ref }}\right) S\left(R_{\text {ref }}\right)\right]^{2}}=\frac{\sigma_{N O E}^{i s}\left(R_{i s}\right)}{\sigma_{N O E}^{i s}\left(R_{\text {ref }}\right)}=\frac{T_{1}^{i s}\left(R_{\text {ref }}\right)}{T_{1}^{i s}\left(R_{\text {is }}\right)}
$$

where $D_{i s}$ and $S^{2}$ are given in Equations (20) and (25).

The calibration (Equation (42)) is valid only for the same correlation times for $R_{i s}$ and $R_{\text {ref. }}$ When $R_{\text {is }}$ is involved in the internal motion, Equation (39) is true in the liquid state temperature regime when internal motion is much faster than isotropic motion $\left(\tau_{\text {iso }} \gg>\tau_{n}\right)$. Otherwise, the calculated value of $R_{i s}$ from Equation (42) will be false. When the relaxation vectors $R_{i s}=$ const and $R_{r e f}=$ const, undergo isotropic motion only, $\left(S^{2}=1\right)$, then the relation $\frac{R_{i s}^{-6}}{R_{\text {ref }}^{-6}}=\frac{\sigma_{N O E}^{i s}\left(R_{i s}\right)}{\sigma_{\text {NOE }}^{i s}\left(R_{\text {ref }}\right)}=\frac{T_{1}^{i s}\left(R_{\text {ref }}\right)}{T_{1}^{i s}\left(R_{i s}\right)}$ is fulfilled.

\section{Experimental}


The ${ }^{13} \mathrm{C}-T_{1}$ relaxation times were measured on Bruker Avance $(14.09 \mathrm{~T})$ and Varian Unity (7.05 T) spectrometers at temperatures $300 \mathrm{~K}, 305 \mathrm{~K}, 310 \mathrm{~K}, 315 \mathrm{~K}, 320 \mathrm{~K}$. The $T_{1}$ values were obtained by the inversion recovery and the saturation recovery method. Both methods gave the same $T_{1}$ values. The $0.5 \mathrm{M}$ solution of methyl- $\beta$-D-galactopyranoside in DMSO-d6 was degassed by 5-6 freeze-pump-thaw cycles and sealed in 5-mm tubes before use. The results of $T_{1}$ measurements for seven well resolved protonated carbons (chemical shift given in Table 1) are presented in Table 2.

Cross-relaxation experiment 1D NOESY [43, 44] was performed on a Bruker Avance (14.09 T) at $300 \mathrm{~K}, 305 \mathrm{~K}, 310 \mathrm{~K}, 315 \mathrm{~K}, 320 \mathrm{~K}$. The proton-proton cross relaxation rates, $\sigma_{\text {NOE }}$, were measured using the 1D NOESY pulse sequence with the selective excitation obtained with a gaussian-shaped pulse of approximately 80 ms duration [45].

The initial NOE build up rate depends only on the direct cross-relaxation term: $\frac{I_{z}(t)-I_{z}(0)}{S_{z}(0)}(t \rightarrow 0)=\sigma_{N O E}$, where $t$ is the mixing time and $I_{z}(t)-I_{z}(0)$ and $S_{z}(0)$ are the intensities of the NOE -enhanced of spin / and the selectively irradiated signal from spin $S$. The anomeric proton $\mathrm{H}(\mathrm{C} 1)$ was selectively irradiated and the cross-relaxation NOE build-up was monitored from the anomeric proton to the $\mathrm{H}(\mathrm{C} 5)$ proton and to the protons of the methyl group. Series of the spectra with different mixing times were recorded up to 16 different mixing times ranging from $12.2 \mathrm{~ms}$ s to $2 \mathrm{~s}$.

Special care was taken to obtain the spectra at short mixing times so that the cross-relaxation rates $\sigma_{N O E}$, could be determined from the linear extrapolation of the intensities at zero mixing time (initial rate approximation).

\section{Interpretation of results in terms of the theory proposed}




\subsection{Character of the overall tumbling}

The motion of a free rotor in the gas phase can be described by the inertial tensor. It is relatively easy to calculate the moments of inertia about the inertial principal axes by diagonalization of this tensor. A schematic drawing of the methyl- $\beta$-D-galactopyranoside $\left(\mathrm{C}_{7} \mathrm{H}_{14} \mathrm{O}_{6}\right)$ molecule with respect to the inertial principal axis system is shown in Figure 4. The main values of the inertial tensor are $I_{x x}=98110^{-47}\left(\mathrm{~kg} \mathrm{~m}^{2}\right), I_{y y}=112810^{-47}\left(\mathrm{~kg} \mathrm{~m}^{2}\right)$ and $I_{z z}=192310^{-47}\left(\mathrm{~kg} \mathrm{~m}^{2}\right)$. Thus, the anisotropy of this tensor is $I_{y y} / I_{x x}=1.15, I_{z z} / I_{x x}=1.96$ and ,$I_{z z} / I_{y y}=1.7$. A rough approximation of the shape of this molecule can be a symmetrical top with $I_{x x} \approx I_{y y}<I_{z z}$. The orientation of the principal axis of the diffusion tensor or the diffusion constant coincides with that of the inertial tensor principal axes. The $\mathrm{z}$ axis is the major axis of the molecule. The anisotropy of the diffusion tensor of the overall motion is expected to be of the same magnitude.

The ${ }^{13} \mathrm{C}$ NMR spectrum of methyl- $\beta$-D-galactopyranoside consists of seven well distinguished resonances of the ${ }^{13} \mathrm{C}$ carbons at the chemical shift given in Table 1 . The ${ }^{13} \mathrm{C} T_{1}$ values at the magnetic fields $B_{0}=7.05 \mathrm{~T}$ and $B_{0}=14.09 \mathrm{~T}$ for carbons $\mathrm{C} 1$ to $\mathrm{C} 6$ are the same in the limit of experimental error at a given temperature. The steady state NOE values at all temperatures, approach the asymptotic value of 2.988 to within experimental error, indicating that these carbons relax predominantly via dipole-dipole interactions and that the extreme narrowing case $\omega \tau<<1$ is fulfilled. The values of the ${ }^{13} \mathrm{C}$ relaxation time $T_{1}^{i s}$ (Table 2 and points in Figure 6) can be obtained from the experimental values of $T_{1}$ of a given carbon atom according to Equation (8). Methylene carbon atom C6 is bound to two protons and C7 carbon - to three methyl protons. Therefore, the $T_{1}^{i s}=2 T_{1}$ for C6 and $T_{1}^{i s}=3 T_{1}$ for C7.

At first it should be established if the overall motion of the $\mathrm{C}_{7} \mathrm{H}_{14} \mathrm{O}_{6}$ molecule in solution is isotropic or anisotropic. The C6-H and C7-H carbon-hydrogen $\mathbf{R}_{\text {is }}$ vectors are 
supposed to participate in the internal motion, therefore, to establish the anisotropy of the overall motion, the $T_{1}^{i s}$ relaxation times of carbons $\mathrm{C} 1$ to $\mathrm{C} 5$ only should be taken into account. The angles $\alpha_{\text {is }}$ between individual C-H vectors are calculated and listed in Table 1. As follows from Equation (5) with (30), the ${ }^{13} \mathrm{C} T_{1}^{i s}$ relaxation time is a function of $\alpha_{\text {is }}$ angle. We propose the following method for distinction between the isotropic and anisotropic overall motions. Lines in Figure 5 represent the theoretical dependencies of $T_{1}^{i s}$ (Equation (5) and (30)) with the fixed value $\left.D_{\perp}=5 \times 10^{15} \exp \left(\frac{2900}{T}\right)\left[s^{-1}\right]\right)$ as a function of $\alpha_{\text {is }}$ for chosen ratios $D_{/ /} / D_{\perp}$ (equal $\left.1,2,3,4,5\right)$ and $R_{i s}=0.105 \mathrm{~nm}$. Points are the values of $T_{1}^{i s}$ for individual carbon atoms $\mathrm{C} 1, \mathrm{C} 2, \mathrm{C} 3, \mathrm{C} 4$ and $\mathrm{C} 5$ at $\mathrm{B}=14.09 \mathrm{~T}$ (Table 2). These $\mathrm{C} 1-\mathrm{H}$ to $\mathrm{C} 5$ $\mathrm{H} \mathbf{R}_{\text {is }}$ vectors are involved in overall motion only. The angles of $\alpha_{\mathrm{is}}$ between particular C-H vectors have been calculated on the basis of the structural data [46] and are listed in Table 1. The $T_{1}^{i s}\left(\alpha_{\text {is }}\right)$ dependence presented in Figure 5, suggests that the motion of the molecule is not anisotropic. The distribution of experimental $T_{1}^{i s}$ values around the theoretical curve for $\mathrm{D}|| / \mathrm{D}_{\perp}=1$ can be caused by different $\mathrm{C}-\mathrm{H}$ bonds lengths and the experimental error.

\subsection{C-H bonds lengths and overall motion parameters from 13-C longitudinal} relaxation

The spin lattice relaxation of the carbons $\mathrm{C} 1, \mathrm{C} 2, \mathrm{C} 3, \mathrm{C} 4$ and $\mathrm{C} 5$ is governed by the isotropic overall motion only. Assuming the $T_{1}^{i s}$ relaxation time of $\mathrm{C} 1$ protonated carbon as the $T_{1}^{i s}\left(R_{r e f}\right)$, where $R_{\text {ref }}$ is the $\mathrm{C} 1-\mathrm{H}$ distance of $0.105 \mathrm{~nm}$, the other $\mathrm{C}-\mathrm{H}$ distances can be calculated from Equation (42) and the relaxation time measured (Table 2). The value of $S\left(R_{i s}\right)^{2}$ equals 1 for $\mathrm{C} 2-\mathrm{H}$ to $\mathrm{C} 5-\mathrm{H}$ relaxation vectors and also $S\left(R_{\text {ref }}\right)^{2}=1$ for the reference 
vector $\mathrm{C} 1-\mathrm{H}$. The values $\mathrm{C}-\mathrm{H}$ are presented in Table 2 for each measured value of ${ }^{13} \mathrm{C} T_{1}^{i s}$. As follows from Table 2, the average values of $\mathrm{C} 2-\mathrm{H}, \mathrm{C} 3-\mathrm{H}$ and $\mathrm{C} 4-\mathrm{H}$ distances are with very high accuracy of $(0.1040 \pm 0.0003) \mathrm{nm}$. The C5-H distance $(0.1020 \pm 0.0003) \mathrm{nm}$ is shorter than the others.

For methyl- $\beta$-D-galactopyranoside the internal motions parameters are known [47]. In solid methylpyranosides the $\mathrm{CH}_{2} \mathrm{OH}$ group occurs in the rotameric form $\left(\mathrm{G}^{-}\right),(\mathrm{T}),(\mathrm{G}+)$ [48]. In the $\left(\mathrm{G}^{-}\right)$and $\left(\mathrm{G}^{+}\right)$orientations the $\mathrm{CH}_{2} \mathrm{OH}$ group rotates about the $\mathrm{C} 5-\mathrm{C} 6$ bond at about $\pm 120^{\circ}$ from the $\mathrm{T}$ orientation. Thus the $\mathrm{CH}_{2} \mathrm{OH}$ group undergoes conformational motion of trans-gauche type, characterized by the activation energy $E_{2}=34 \mathrm{~kJ} / \mathrm{mol}$ and $\tau_{0}^{2}=2 \times 10^{-12} \mathrm{~s}$ [47] (Table 3). The activation energy for internal motion can be also determined by the atom atom potential method for the isolated molecule. Therefore, it seems that the motional parameters $E_{2}$ and $\tau_{0}^{2}$ obtained for solid state are the same when the molecule is in liquid state. For such parameters the maximum of the spectral density of the internal motion of $\mathrm{CH}_{2} \mathrm{OH}$ group is not well separated from the maximum of the isotropic overall motion. As follows from Table 3, the frequency of the internal motion of $\mathrm{CH}_{2} \mathrm{OH}$ group is lower than that of the overall tumbling $\left(\tau_{2}>\tau_{\text {iso }}\right)$. Therefore, the effect of the conformational motion of $\mathrm{CH}_{2} \mathrm{OH}$ group on the $T_{1}^{i s}$ value of $\mathrm{C} 6$ carbon should not be expected (see Figure3). The greater value of $T_{1}^{i s}$ of carbon C6 must be a consequence of the length of the C6-H bond greater than those of the $\mathrm{C} 1-\mathrm{H}$ to $\mathrm{C} 5-\mathrm{H}$ bonds. Assuming again the $\mathrm{C} 1$ anomeric carbon as the reference carbon $\left(\mathrm{S}\left(\mathrm{R}_{\mathrm{ref}}\right)^{2}=1\right)$ and $\mathrm{S}\left(\mathrm{R}_{\mathrm{C} 6-\mathrm{H}}\right)^{2}=1$, the C6-H distance can be calculated from Equation (42), and the measured relaxation time of C6 carbon. The C6-H distance obtained of $(0.1120 \pm 0.0003) \mathrm{nm}$ is the longest $\mathrm{C}-\mathrm{H}$ distance in molecule (Table 2).

The methyl group undergoes hindered rotation and the parameters of this motion are $E_{3}=4.2 \mathrm{~kJ} / \mathrm{mol}$ and $\tau_{0}^{3}=3.8 \times 10^{-13} \mathrm{~s}$ [47]. The $T_{1}^{i s}$ relaxation time of carbon C7 (Table 2) 


\subsection{Correlation times}

\section{being significantly longer than for the other carbons is a result of the methyl group internal} motion. The hindered rotation of $\mathrm{CH}_{3}$ group is responsible for a minimum of $T_{1}^{i s}$ of carbon $\mathrm{C} 7$ in low temperatures and influences the $T_{1}^{i s}$ minimum at high temperatures. The motional parameters obtained for the methyl group in paper [47] prove that this internal motion $\left(\mathrm{C}_{3}\right)$ is faster than the overall tumbling. To calculate the $\mathrm{C} 7-\mathrm{H}$ distance (identical for the three $\mathrm{C}-\mathrm{H}$ bonds in the $\mathrm{CH}_{3}$ group) we have to insert $S\left(R_{i s}\right)^{2}=0.11$ and $S\left(R_{r e f}\right)^{2}=1$ into Equation (42). The C7-H distance of $(0.1011 \pm 0.0003) \mathrm{nm}$ or $(0.1040 \pm 0.0003) \mathrm{nm}$ has been obtained from the measurements at $\mathrm{B}_{0}=14.09 \mathrm{~T}$ or $\mathrm{B}_{0}=7.05 \mathrm{~T}$ respectively. The value obtained for the lower magnetic field of $7.05 \mathrm{~T}$ seems to be more reliable. The little shorter relaxation times $T_{1}^{i s}$ at $B_{0}=14.09 \mathrm{~T}$ than at $B_{0}=7.05 \mathrm{~T}$ reveal some additional contribution to the relaxation rate. The source of this contribution can be the spin-rotational mechanism of relaxation [49]. The $\mathrm{C}-\mathrm{H}$ distances (except $\mathrm{C} 7-\mathrm{H}$ bond) obtained from the $13 \mathrm{C}$ relaxation data are of high accuracy and it seems that this method can be treated as highly reliable for determination of these distances. The comparison of $\mathrm{C}-\mathrm{H}$ bonds lengths obtained in the present paper with these given in [46] is presented in Table 4.

The best fits of Equation (5) with (28) for C1 to C5 and Equation (24) for C6 and C7 to the experimental data of ${ }^{13} \mathrm{C} T_{1}^{i s}$ are given in Figure 6 by solid lines. The calculated $\mathrm{C}-\mathrm{H}$ distances (Table 4), $S_{3}=0.11 d_{C 7-H^{2}}$ (eq. (23), $\left.\Theta_{3}^{C 7-H}=109.4^{0}\right), S_{2}=0.44 d_{C 6-H^{2}}$ (Equation (22), $\Theta_{2}^{C 6-H}=120^{\circ}$ ) and motional parameters of the internal motions (Table 3) were used for this fit. The fitted parameters were $E_{\text {iso }}$ and $\tau_{0}^{i s o}$. Two series of experimental data were fitted $\left(B_{0}=7.05 \mathrm{~T}-\right.$ Figure $6 \mathrm{a}$ and $B_{0}=14.09 \mathrm{~T}-$ Figure $\left.6 \mathrm{~b}\right)$. The best fit parameters $\left(E_{\text {iso, }} \tau_{0}^{i s o}\right)$ are listed in Table 3. 
The values of $E_{\text {iso }}$ and $\tau_{0}^{\text {iso }}$ obtained from the best fit (Table 3 ) were used to draw the theoretical plot of the temperature dependence of the overall correlation time (Equation (27)), presented in Figure 7 by the solid line \#1. The points are the values of correlation times $\tau_{\text {iso }}$ for the particular experimental values of ${ }^{13} \mathrm{C} T_{1}^{i s}$. The lines \# 2 and \#3 (correlation times of internal motions) are calculated on the basis of the motion parameters given in Table 3 and Equation (12). As shown in Figure 7, only the correlation time of the $\mathrm{CH}_{3}$ group, $\tau_{3}(\# 2)$, is much shorter while the correlation time of the $\mathrm{CH}_{2} \mathrm{OH}, \tau_{2}(\# 3)$, is much longer than $\tau_{\text {iso }}(\# 1)$.

4.4 Proton - proton distances and homonuclear cross-relaxation rate.

In the 1D NOESY spectra of methyl- $\beta$-D-galactopyranoside the Overhauser effect between $\mathrm{H}(\mathrm{C} 1)$ to $\mathrm{H}(\mathrm{C} 5)$ and to $\mathrm{H}(\mathrm{C} 7)$ was observed. The chemical shifts of protons $\mathrm{H}(\mathrm{C} 1)$, $\mathrm{H}(\mathrm{C} 5)$ and $\mathrm{H}(\mathrm{C} 7)$ are $3.97,3.32$ and $3.37 \mathrm{ppm}$ respectively. The ${ }^{1} \mathrm{H},{ }^{1} \mathrm{H}$ cross-relaxation buildup curves from 1D NOE experiments obtained by selective excitation of anomeric proton $\mathrm{H}(\mathrm{C} 1)$ are linear for short mixing times (up to about $0.3 \mathrm{~s}$ ). For long mixing times, these build-up curves deviate from linearity. The cross-relaxation rate $\sigma_{N O E}^{i s}$ has been obtained by the initial build-up rate approximation. The dipolar interactions between spin " $i "-\mathrm{H}(\mathrm{C} 1)$ and three methyl spins "s" $-\mathrm{H}(\mathrm{C} 7)$ contribute to the proton-proton cross-relaxation rate $\mathrm{H}(\mathrm{C} 1)$, H(C7) (Equation (9))

The value of $\sigma_{N O E}$ from $300 \mathrm{~K}$ to $320 \mathrm{~K}$ is $(0.067 \pm 0.005) \mathrm{s}^{-1}$, for protons " $i$ " and " $s$ " bonded to carbons $\mathrm{C} 1$ and $\mathrm{C} 5$ (circles in Figure 8a). The proton spin pair $\mathrm{H}(\mathrm{C} 1)-\mathrm{H}(\mathrm{C} 5)$ is not involved in the internal motion therefore, Equation (7) with (24) can be applied for this fit. 
The value of $\sigma_{N O E}$ obtained from the initial build-up rate approximation from $300 \mathrm{~K}$ to $320 \mathrm{~K}$ is $(0.050 \pm 0.005) \mathrm{s}^{-1}$ for proton " $p$ " and three protons " $s$ " bonded to carbons $\mathrm{C} 1$ and $\mathrm{C} 7$, respectively (circles in Figure $8 b$ ). The proton spin $\mathrm{H}(\mathrm{C} 7)$ is involved in the internal motion hindered rotation of methyl group. Therefore, the interproton distance $R_{\text {is }}$ between $\mathrm{H}(\mathrm{C} 1)$ and each methyl spin $\mathrm{H}(\mathrm{C} 7)$ takes three different values $R_{i s}(A), R_{i s}(B), R_{i s}(C)$ and jump angles $\Theta_{A B}^{i s}, \Theta_{A C}^{i s}, \Theta_{B C}^{i s}$. The theoretical values of $\sigma_{N O E}^{i s}$ were calculated from the Equation (7) where $J_{i s}^{m}(\omega)$ is given in Equation (24) and also $E_{i s o}, \tau_{0}^{\text {iso }}, E_{3}, \tau_{0}^{3}$ were assumed from Table 3. The values of $R_{i s}(A), R_{i s}(B), R_{i s}(C)$ are closely related to the $\mathrm{C} 1-\mathrm{H}$ and $\mathrm{C} 7-\mathrm{H}$ bond lengths and orientations which are known from the crystallographic data [46]. It seems that the orientation angles obtained from the crystallographic data are more accurate than the lengths of the carbon - hydrogen bonds. For example the crystallographic data indicate three different $\mathrm{C}-\mathrm{H}$ bond lengths in the methyl group which seems strange (Table 4). Keeping the orientation angles obtained from the crystallographic data, the distances $\mathrm{C} 5-\mathrm{H}$ and $\mathrm{C} 7-\mathrm{H}$ can be calculated from the best fit of $\sigma_{\text {NOE }}^{\text {is }}$ to the theoretical equation 7. These distances were only one of the best fit parameter. They identical with these obtained from the ${ }^{13} \mathrm{C} \mathrm{T}_{1}$ experiment and they are listed in Table 4. The distances $\mathrm{H}(\mathrm{C} 1)-\mathrm{H}(\mathrm{C} 5), \mathrm{H}(\mathrm{C} 7)$ - three methyl protons and jump angles $\Theta_{X Y}^{i s}$ where $X, Y=A, B$, and $C$ were calculated individually for each equilibrium site of $X, Y$. The theoretical dependences of $\sigma_{\text {NOE }}^{i s}$ are presented in Figure 8a and $8 \mathrm{~b}$ by solid lines. The agreement between the theoretical and experimental cross relaxation rates $\sigma_{N O E}^{\text {is }}$ is satisfactory.

\section{Conclusions}


Analysis of our experimental data for methyl - $\beta$-D-galactopyranoside and their interpretation in terms of equations describing the nuclear magnetic relaxation of a spin system undergoing a complex motion permits drawing the following conclusions.

1. The maximum of the temperature dependence of the spectral density $(7.05 \mathrm{~T}$ and $14.09 \mathrm{~T}$ ) of the methyl group internal rotation appears at low temperatures and is well separated from the maximum of the spectral density of the isotropic motion $\left(\tau_{3}<<\right.$

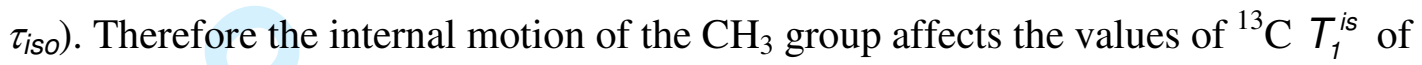
C7 methyl - $\beta$-D-galactopyranoside carbon at high temperatures.

2. The maximum of the spectral density $(7.05 \mathrm{~T}$ and $14.09 \mathrm{~T})$ of the conformational trans - gauche jumps of $\mathrm{CH}_{2} \mathrm{OH}$ is not well separated from the maximum of the spectral density of the overall motion of methyl $-\beta$-D-galactopyranoside molecule. The slow internal motion of $\mathrm{CH}_{2} \mathrm{OH}$, slower than overall motion, does not influence the values of $T_{1}^{\text {is }}$ of C6 carbon.

3. The ${ }^{13} \mathrm{C} T_{1}$ relaxation time is a powerful tool to determine the $\mathrm{C}-\mathrm{H}$ bond length to a high accuracy.

4. The overall motion of the methyl- $\beta$-D-galactopyranoside molecule is isotropic. The agreement between the theoretical and experimental cross relaxation rates of spin pairs $\mathrm{H}(\mathrm{C} 1)$ - three methyl protons is satisfactory when the theoretical equation for the spectral density takes into account fluctuations of the magnitude of the $\boldsymbol{R}_{\boldsymbol{i s}}$ vectors caused by the motion of the methyl protons.

5. The "model - free approach" gives true values of the order parameter $S^{2}$, only when internal motion is very fast (tens times shorter correlation time $\tau_{n}$ in comparison to overall $\tau_{i s o}$ ). The dependence of the spectral density on the product $D_{i s}{ }^{2} S^{2}$ is the reason for the problems in distinguishing between changes in the relaxation rates 
appearing in response to the changes in $D_{i s}$ or $S^{2}$ separately. Often the values of $S^{2}$ in the range $0.75<S^{2}<1$ reflects the differences in the $\mathrm{C}-\mathrm{H}$ bonds lengths.

This paper is dedicated to the memory of the NMR relaxation big specialist Donald Eduard Woessner (1930 - 2008).

\section{References}

[1] I. Solomon, Phys. Rev. 99, 559 (1955).

[2] D. Neuhaus, M. P. Williamson, The Nuclear Overhauser Effect in Structural and Conformational Analysis, John Wiley\&Sons, Inc., Publication (2000).

[3] J. Cavanagh, W. J. Fairbrother, A. G. Palmer III, N. J. Skelton, Protein NMR Spectroscopy, Academic Press; San Diego (1996).

[4] Noggle, J. S.; Schirmer, R. E. The Nuclear Overhauser Effect. Chemical Applications, Academic Press, New York (1971).

[5] R. Brüschweiler, D. A. Case, Progress in NMR Spectroscopy, 26, 27 (1994).

[6] R. R. Ernst, G. Bodenhausen, A. Wokaun, Principles of NMR in One and Two Dimensions, Clarendon Press: Oxford (1987).

[7] K. E. Köver, G. Batta, Prog. Magn. Reson. 19, 223 (1987).

[8] G. Wagner and K. Wüthrich, J. Magn. Reson. 33, 675 (1979).

[9] B. Celda, C. Biamonti, M. J. Arnau, et al., J. Biomom NMR 5, 161 (1995).

[10] C. Mumenthaler, P. Gunert, W. Braun et al., J. Biomol. NMR 10, 351 (1997).

[11] A. A. Bothner-By, R. L. Stephens, J. Lee, et al., J. Am. Chem. Soc. 106, 811, (1984).

[12] P. Debye, Polar Molecules, Dover Publications, New York (1949).

[13] J. D. Hoffmann, H. G. Pfeifer, J. Chem. Phys. 22, 132 (1954).

[14] J. D. Hoffman, J. Chem. Phys. 23, 1331 (1955). 
[15] D. E. Woessner, J. Chem. Phys. 1, 36 (1962).

[16] D. E. Woessner, J. Chem. Phys. 37, 647 (1962).

[17] D. E. Woessner, J. Chem. Phys. 42, 1855 (1965).

[18] D. J. Wallach, Chem. Phys. 47, 5258 (1967).

[19] M. J. Dellwo and A. J. Wand, J. Am. Chem. Soc. 115, 1886 (1993).

[20] S. Nagaoka, T. Terao, F. Imashiro et al., J. Chem. Phys. 79, 4694 (1983).

[21] E. R. Andrew and L. Latanowicz, J. Magn. Reson. 68, 232 (1986).

[22] L. Latanowicz, Ber. Bunsenges Phys. Chem. 91, 237 (1987).

[23] L. Latanowicz and Z. Pajak, Ber. Bunsenges Phys. Chem. 93, 1440 (1989).

[24] L. Latanowicz, E. R. Andrew and E. C. Reynhardt, J. Magn. Reson. A 107, 194 (1994).

[25] L. Latanowicz and Z. Pajak, Mol. Phys. 82, 1187 (1994).

[26] L. Latanowicz and E. C. Reynhardt, J. Magn. Reson. A 121, 23 (1996).

[27] L. Latanowicz and E. C. Reynhardt, Mol. Phys. 90, 107 (1997).

[28] J. Tropp, J. Chem. Phys. 72, 6035 (1980).

[29] G. Lipari and A. Szabo, J. Am. Chem. Soc. 104, 4546 (1982).

[30] G. Lipari and A. Szabo, J. Am. Chem. Soc. 104, 4559 (1982).

[31] A. Abragam, Principles of Nuclear Magnetism, Oxford University Press, Oxford (1961).

[32] N. Bloembergen, E. M. Purcell and R. V. Pound, Phys. Rev. 73, 679 (1948).

[33] W. T. Huntress, J. Chem.. Phys. 48, 3524 (1968).

[34] P. S. Hubbard, J. Chem. Phys. 52, 563(1970).

[35] D. C. Canet, Concepts Magn. Reson. 10, 291(1998).

[36] P. Bernatowicz, J. Kowalewski and D. Sandström, J. Phys. Chem. A 109, 57 (2005).

[37] P. Bernatowicz, J. Kowalewski and S. Szymański, J. Chem. Phys. 124, 024108 (2006).

[38] G. C. Levy, D. J. Craik and B. Norden, et al., J. Am. Chem. Soc. 104, 25 (1982).

[39] D. Kotsyubynskyy and A. Gryff-Keller, J. Phys. Chem. A 111, 1179 (2007). 
[40] F. Massi, A. G. Palmer, J. Am. Chem. Soc. 125, 11158 (2002).

[41] A. G. Palmer. Chem. Rev. 104, 3623 (2004).

[42] E. Johnson, A. G. Palmer, M. Rance, Proteins 66, 762 (2007).

[43] J. Jeener, B. H. Meier, P. Bachmann and R. R. Ernst, J. Chem. Phys. 71, 4546 (1979).

[44] M. P. Williamson and D. Neuhaus, J. Magn. Reson. 72, 369 (1987).

[45] H. Kessler, H. Oschkinat, C. Griesinger et al., J. Magn. Reson. 70, 106 (1986).

[46] S. Takagi and G. A. Jeffrey, Acta Crystallogr., Sect B: Struct. Crystallogr. Cryst. Chem. 34, 2006 (1978).

[47] L. Latanowicz, E. C. Reynhardt, R. Utrecht et al., Ber. Bunsenges Phys. Chem. 99, 152 (1995).

[48] E. W. Korolik, N. Iwanowa and R. G. Zubankow, Zhurn. Prikl. Spektr. 52, 250 (1990).

[49] H. S. Gutowsky, I. J. Lawrenson and K. Shimomura, Phys. Rev. Lett. 6, 349 (1961). 


\section{Figure Captions}

Fig. 1

The values of the order parameter $S^{2}$ for two (solid line) and three (dashed line) site jumps of $\boldsymbol{R}_{\text {is }}$ vector as a function of jump angle $\Theta_{n}^{i s}$, where $\mathrm{n}=2$ and 3

Fig. 2

The values of parameter $S^{2}$ (Equation (41)), as a function of the ratio $\left(\tau_{3} / \tau_{\text {iso }}\right)$.

$\left(\tau_{\text {iso }}=1.6 \times 10^{-14} \exp \left(\frac{2460}{T}\right)[s]\right)$.

Fig. 3

The illustration of temperature dependence of ${ }^{13} \mathrm{C} T_{1}^{\text {is }}(7.05 \mathrm{~T})$ influenced the complex motion (Equations (5) and (24)). The $R_{i s}$ vector $\left(R_{i s}=0.112 \mathrm{~nm}\right)$ performs the isotropic overall motion $\left(E_{\text {iso }}=20.5 \mathrm{~kJ} / \mathrm{mol}\right.$ and $\left.\tau_{o}^{i s o}=1.6 \times 10^{-14} \mathrm{~s}\right)$ and the $\mathrm{C}_{3}$ internal motion $\left(\tau_{0}^{3}=4 \times 10^{-13} \mathrm{~s}\right)$. Different activation energies $E_{3}$ for the internal motion were assumed:

2kJ/mol - \#1, $5 \mathrm{~kJ} / \mathrm{mol}$ - \#2, $10 \mathrm{~kJ} / \mathrm{mol}$ - \#3, $20 \mathrm{~kJ} / \mathrm{mol}$ - \#4). Plot \#5 represents $T_{1}^{\text {is }}$ for the case of the isotropic overall motion only (Equations (5) and (28)). $\Theta_{3}^{i s}=109.4^{0}$

Fig. 4

Molecular geometry of methyl- $\beta$-D-galactopyranoside with respect to the inertial principal axis system $x, y, z$. Inertial and rotational diffusion principal axis systems are assumed to be coincident. The rotor behaviour can be approximated by that of a symmetric-top rotor with the $D_{/ /}$and $D_{\perp}$ coefficients as shown. Dashed lines show the distances from the anomeric proton $\mathrm{C} 1(\mathrm{H})$ to the proton at $\mathrm{C} 5(\mathrm{H})$ and to the methyl protons.

Fig. 5

Lines represent the theoretical (with fixed value $\left.D_{\perp}=1 \times 10^{13} \exp \left(\frac{2460}{T}\right)\left[\mathrm{s}^{-1}\right]\right)$

dependences of $T_{1}^{\text {is }}(7.05 \mathrm{~T})$ as a function of $\alpha_{\mathrm{is}}$ for chosen ratios of $D_{/ /} / D_{\perp}$ (equal $1,2,3,4$, 
5) (Equations (5) and (30)). The points correspond to the values of $T_{1}^{\text {is }}$ for the separate carbons $\mathrm{C} 1, \mathrm{C} 2, \mathrm{C} 3, \mathrm{C} 4$ and $\mathrm{C} 5$. The values of angles $\left(\alpha_{\mathrm{is}}\right)$ are taken from Table $1 . R_{\text {is }}=$ $0.105 \mathrm{~nm}, \mathrm{~T}=300 \mathrm{~K}(\mathrm{a}), \mathrm{T}=310 \mathrm{~K}(\mathrm{~b}), \mathrm{T}=320 \mathrm{~K}(\mathrm{c})$

Fig. 6

${ }^{13} \mathrm{C}$ spin-lattice relaxation times $T_{1}^{\text {is }}$ as a function of inverse temperature for methyl- $\beta-\mathrm{D}$ galactopyranoside at two magnetic fields 7.05 T (a) and $14.09 \mathrm{~T}$ (b). (o - C1, $\square-\mathrm{C} 2,+-\mathrm{C} 3$, $\times-\mathrm{C} 4, \Delta-\mathrm{C} 5, \nabla-\mathrm{C} 6, \diamond-\mathrm{C} 7)$. Solid lines represent the best fit of Equations (5) and (28) (C1 to $\mathrm{C} 5$ ) or (24) (C6 to C7) to the data. The fitted parameters were $R_{i s}, E_{i s o}, \tau_{0}^{i s o}$. The parameters of the internal motions of $\mathrm{CH}_{2} \mathrm{OH}$ and $\mathrm{CH}_{3}$ (listed in Table 3) are assumed from reference 44 .

Fig. 7

Correlation times of the overall and internal motions of the methyl- $\beta$-D-galactopyranoside molecule in DMSO. The points represent the correlation times $\tau_{\text {iso }}$ for particular experimental values of $T_{1}^{i s}$ given in Table 2 (o - C1, $\square-\mathrm{C} 2, \Delta-\mathrm{C} 3, \nabla-\mathrm{C} 4, \diamond-\mathrm{C} 5,+-\mathrm{C} 6, \times-\mathrm{C} 7$ ), while the lines represent the calculated correlation times: \#1 - $\tau_{\text {iso }}$ (Equation (27)), \#2 - $\tau_{3}$ (Equation (12)), \#3 - $\tau_{2}$ (Equation (12)) which are plotted on the basis of the motional parameters listed in Table 3.

Fig. 8

Temperature dependence of $\mathrm{H}(\mathrm{C} 1)-\mathrm{H}(\mathrm{C} 5)$ (a) and $\mathrm{H}(\mathrm{C} 1)-\mathrm{H}(\mathrm{C} 7)$ (b) cross-relaxation rates, $\sigma_{\text {NOE }}^{\text {is }}$, for methyl- $\beta$-D- galactopyranoside in DMSO (circles). Theoretical curves were fitted using Equations (7) with (28) (a) and ((24) with (23)) (b) and the motional parameters listed in Table 3. The interproton distances $\mathrm{H}(\mathrm{C} 1)-\mathrm{H}(\mathrm{C} 5)$ and $\mathrm{H}(\mathrm{C} 1)-\mathrm{H}(\mathrm{C} 7)$ were calculated from the fitted $\mathrm{C} 5-\mathrm{H}$ and $\mathrm{C} 7$ - three methyl protons distances and space orientation angles taken from the structural data [46]. 
Table 1

${ }^{13} \mathrm{C}$ chemical shift $(\delta, \mathrm{ppm})$ of protonated carbons and the angle made by $\mathrm{C}-\mathrm{H}$ and the main axis of the molecule

\begin{tabular}{|l|l|l|}
\hline Number of carbon & $\begin{array}{l}\text { Chemical shift } \\
\text { (ppm) }\end{array}$ & $\begin{array}{l}\text { Angle between C-H and the } \\
\text { major axis of symmetrical } \\
\text { top. } \\
\text { (degree) }\end{array}$ \\
\hline C1 & 75.612 & 96.07 \\
\hline C2 & 73.887 & 79.65 \\
\hline C3 & 70.978 & 105.15 \\
\hline C4 & 68.629 & 165.74 \\
\hline C5 & 60.936 & 95.51 \\
\hline C6 & 56.254 & \\
\hline C7 & 104.929 & \\
\hline
\end{tabular}




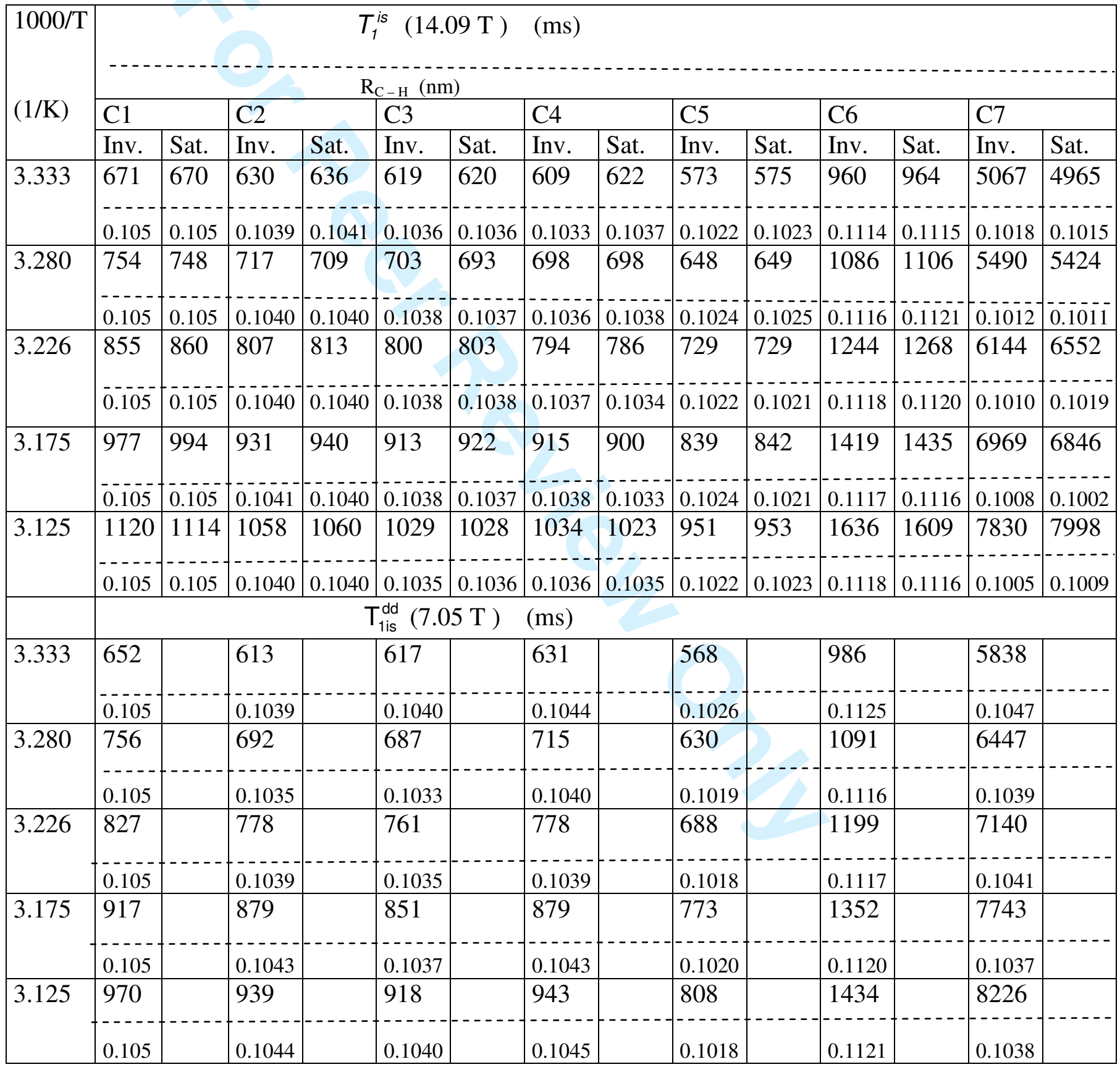

Inv. - method of inversion recovery, Sat. - method of saturation recovery 
Table 3

Motion parameters of methyl- $\beta$-D-galactopyranoside

\begin{tabular}{|l|l|l|}
\hline Motion & Activation energy [kJ/mol] & $\begin{array}{l}\text { Preexponential factor of } \\
\text { correlation time }[\mathrm{s}]\end{array}$ \\
\hline Overall & 20.5 & $1.6 \cdot 10^{-14}$ \\
\hline $\begin{array}{l}\text { Methyl group hindered } \\
\text { rotation* }\end{array}$ & 4.2 & $3.8 \cdot 10^{-13}$ \\
\hline $\begin{array}{l}\text { Methylene group trans- } \\
\text { gauche motion* }\end{array}$ & 34 & $2 \cdot 10^{-12}$ \\
\hline
\end{tabular}

*Data obtained from methyl- $\beta$-D-galactopyranoside studied in solid state [47]

Table 4

Apparent interatomic distances derived from ${ }^{13} \mathrm{C} T_{1}^{\text {is }}(7.05 \mathrm{MHz}, 14.09 \mathrm{MHz})$ and crystallographic data [46] for methyl- $\beta$-D-galactopyranoside.

\begin{tabular}{|l|l|l|}
\hline DISTANCES & $\begin{array}{c}\text { (present paper) } \\
(\mathrm{nm})\end{array}$ & $\begin{array}{l}\text { (crystallographic } \\
\text { data) } \\
\text { (nm) }\end{array}$ \\
\hline $\mathrm{C} 1-\mathrm{H}$ & 0.105 & 0.106 \\
\hline $\mathrm{C} 2-\mathrm{H}$ & 0.104 & 0.108 \\
\hline $\mathrm{C} 3-\mathrm{H}$ & 0.104 & 0.100 \\
\hline $\mathrm{C} 4-\mathrm{H}$ & 0.104 & 0.104 \\
\hline $\mathrm{C} 5-\mathrm{H}$ & 0.102 & 0.111 \\
\hline C7 - H (methyl & 0.104 & 0.091, \\
group) & & 0.088, \\
& & 0.113 \\
\hline C6 - H & 0.112 & 0.106, \\
(methylene & & 0.103 \\
group) & & 0.217 \\
\hline $\mathrm{H}(\mathrm{C} 1)-\mathrm{H}(\mathrm{C} 5)$ & 0.218 & 0.289, \\
\hline $\mathrm{H}(\mathrm{C} 1)-\mathrm{H}(\mathrm{C} 7)^{*}$ & 0.284, & 0.339, \\
& 0.354, & 0.236 \\
\hline
\end{tabular}

*This distance assumes three values corresponding to equilibrium sites during $\mathrm{C}_{3}$ rotation of methyl group. 


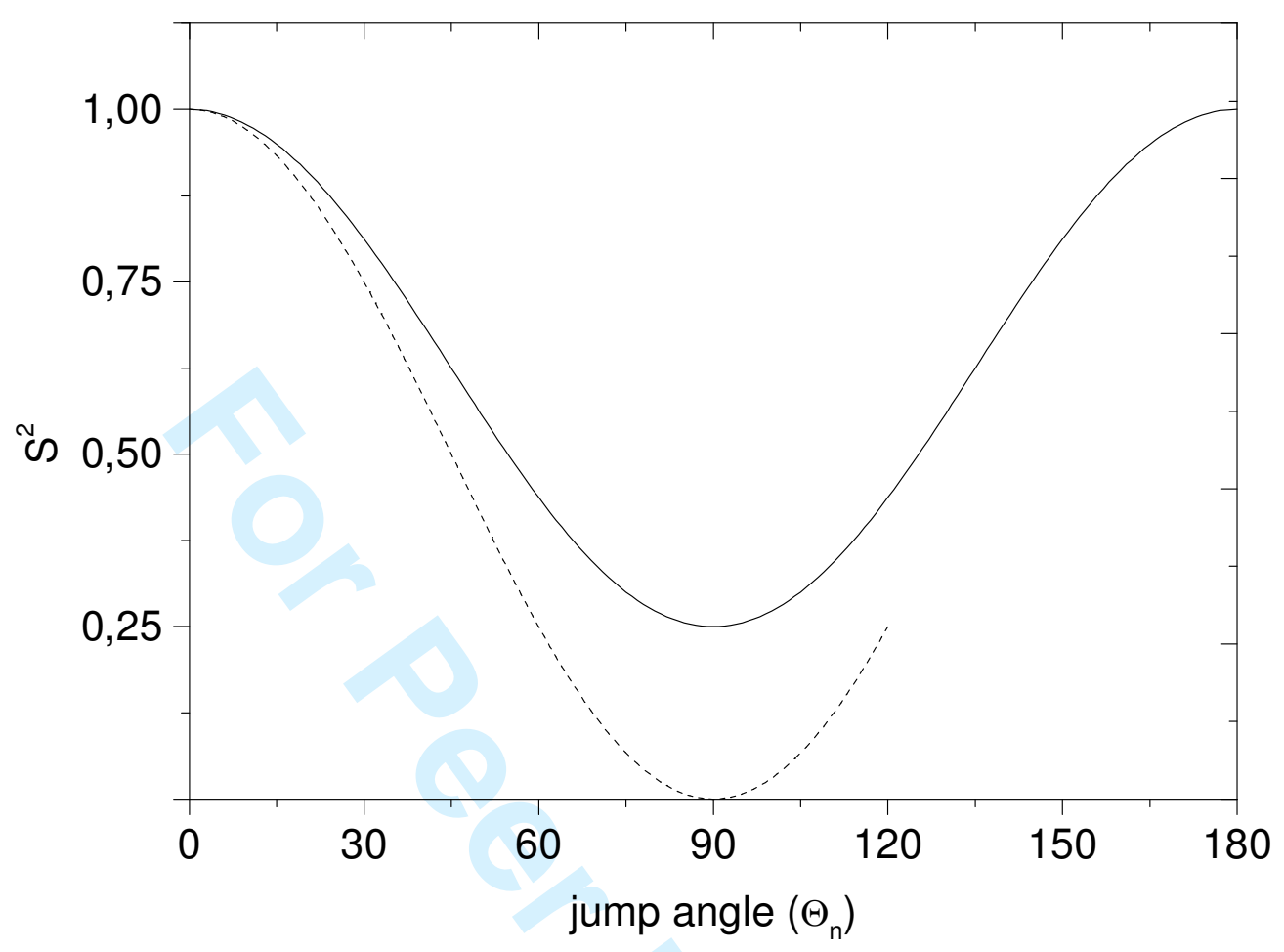

Fig. 1 


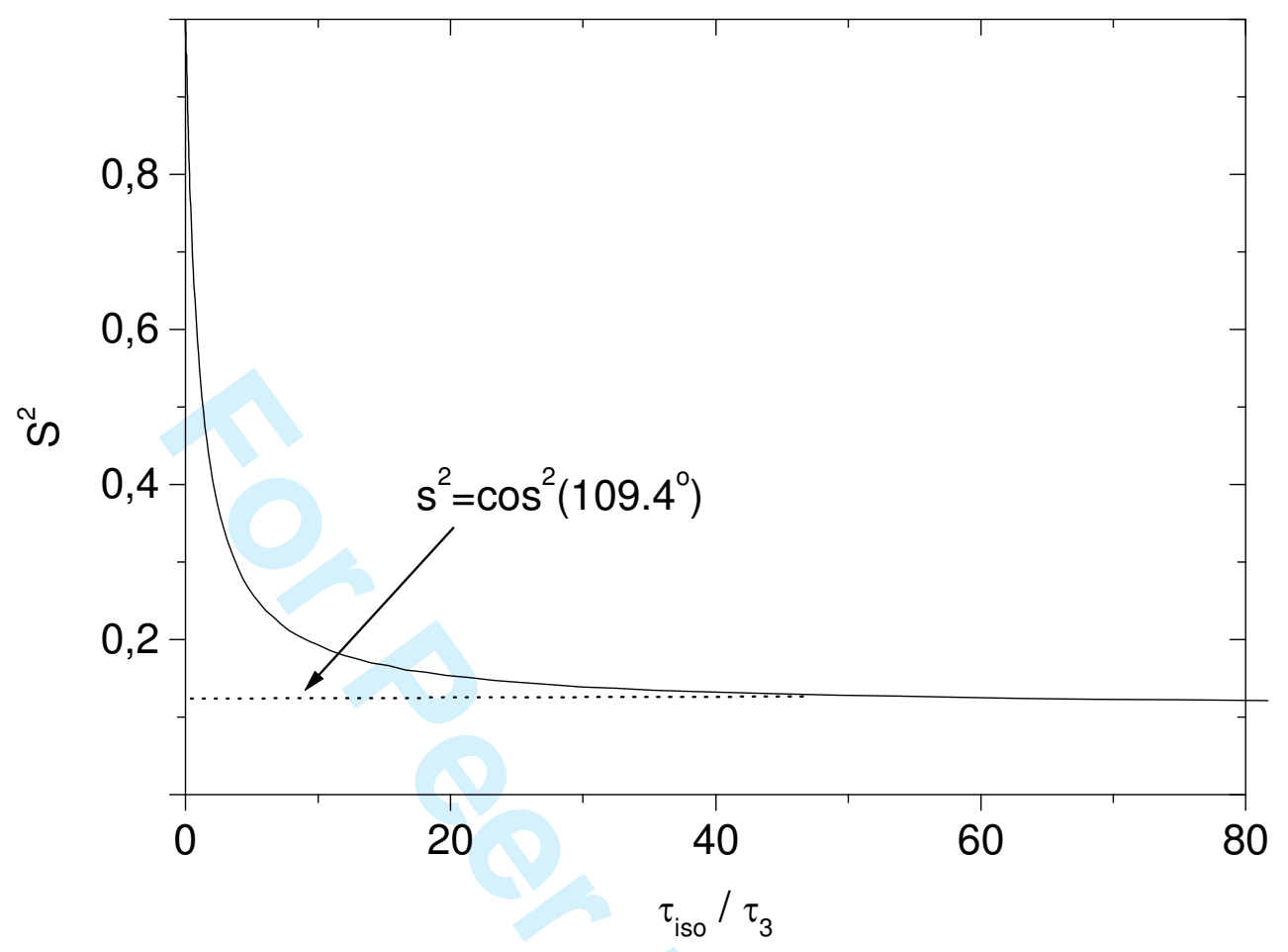

Fig. 2 


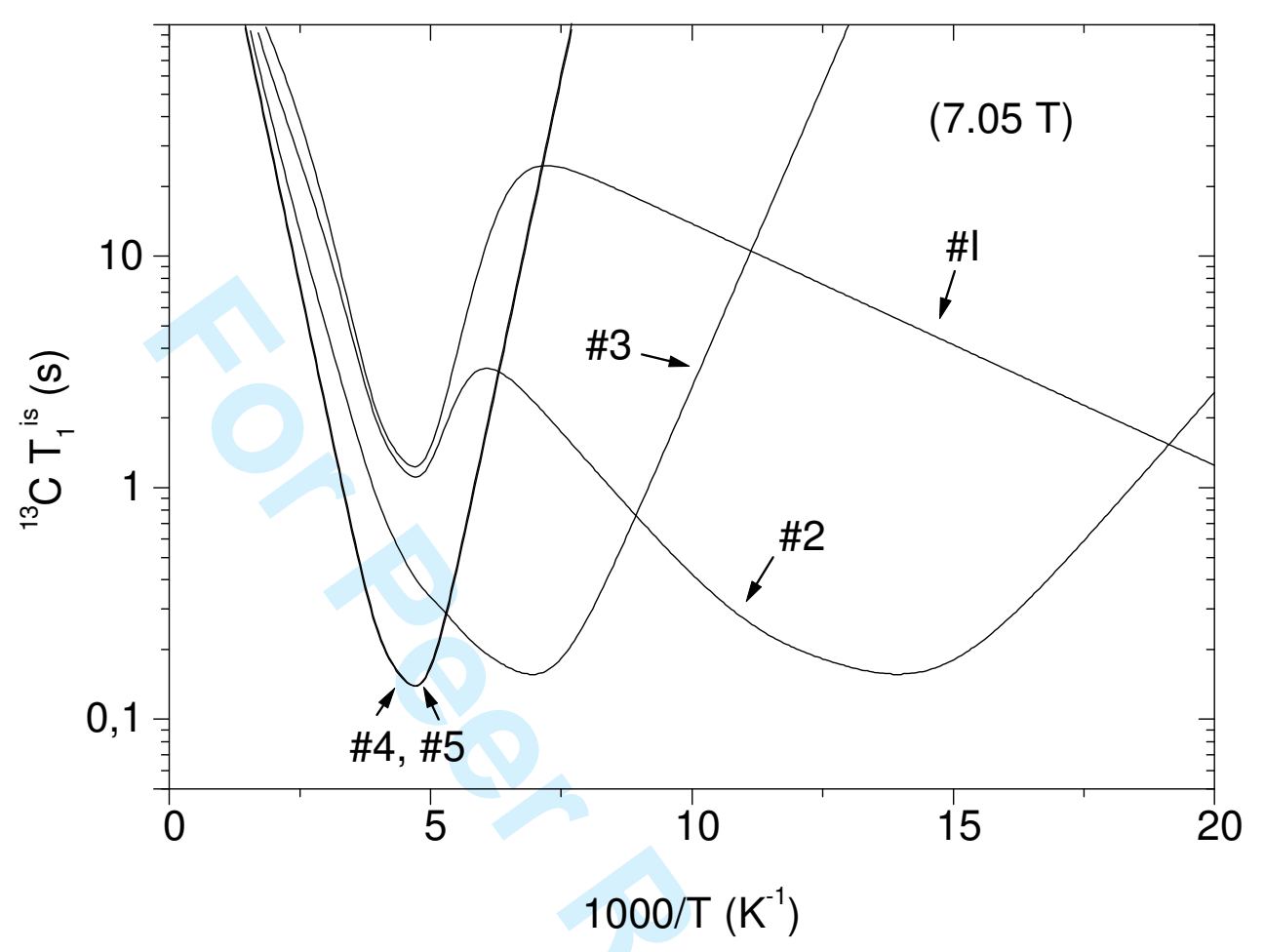

Fig. 3 


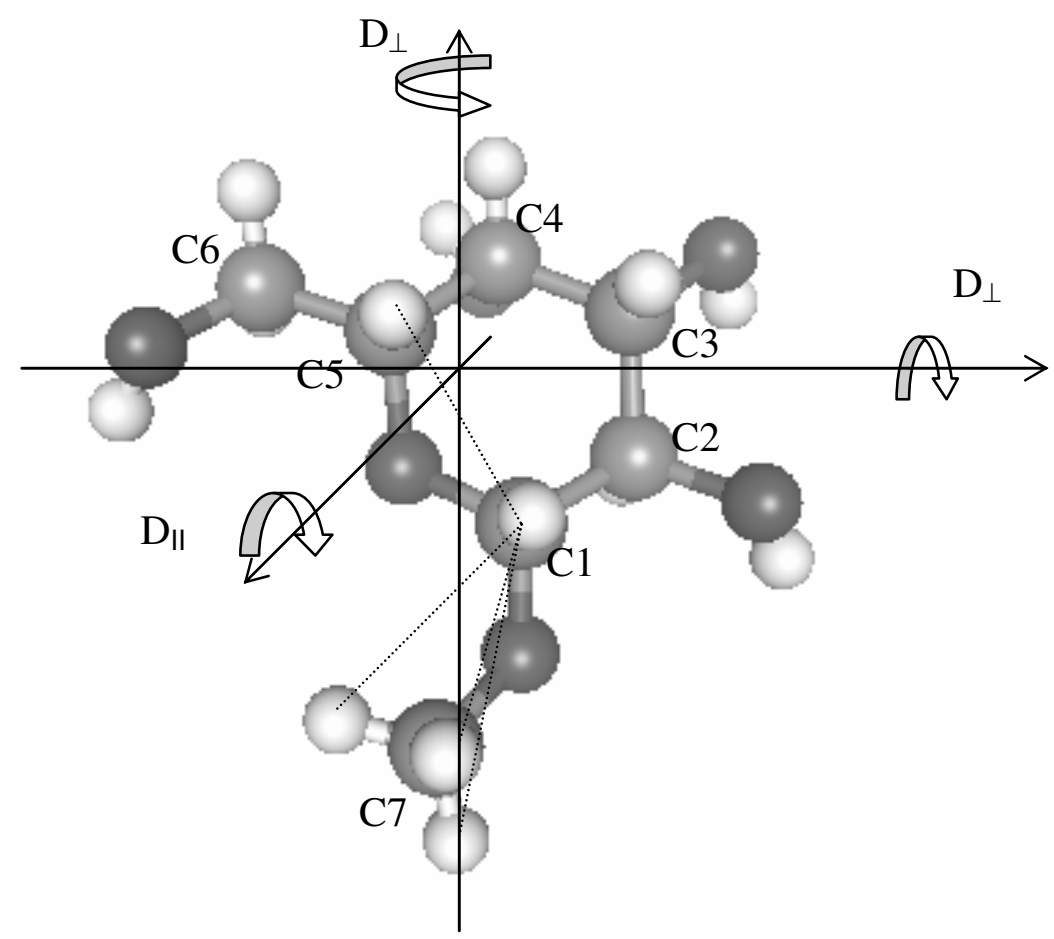

Fig. 4 


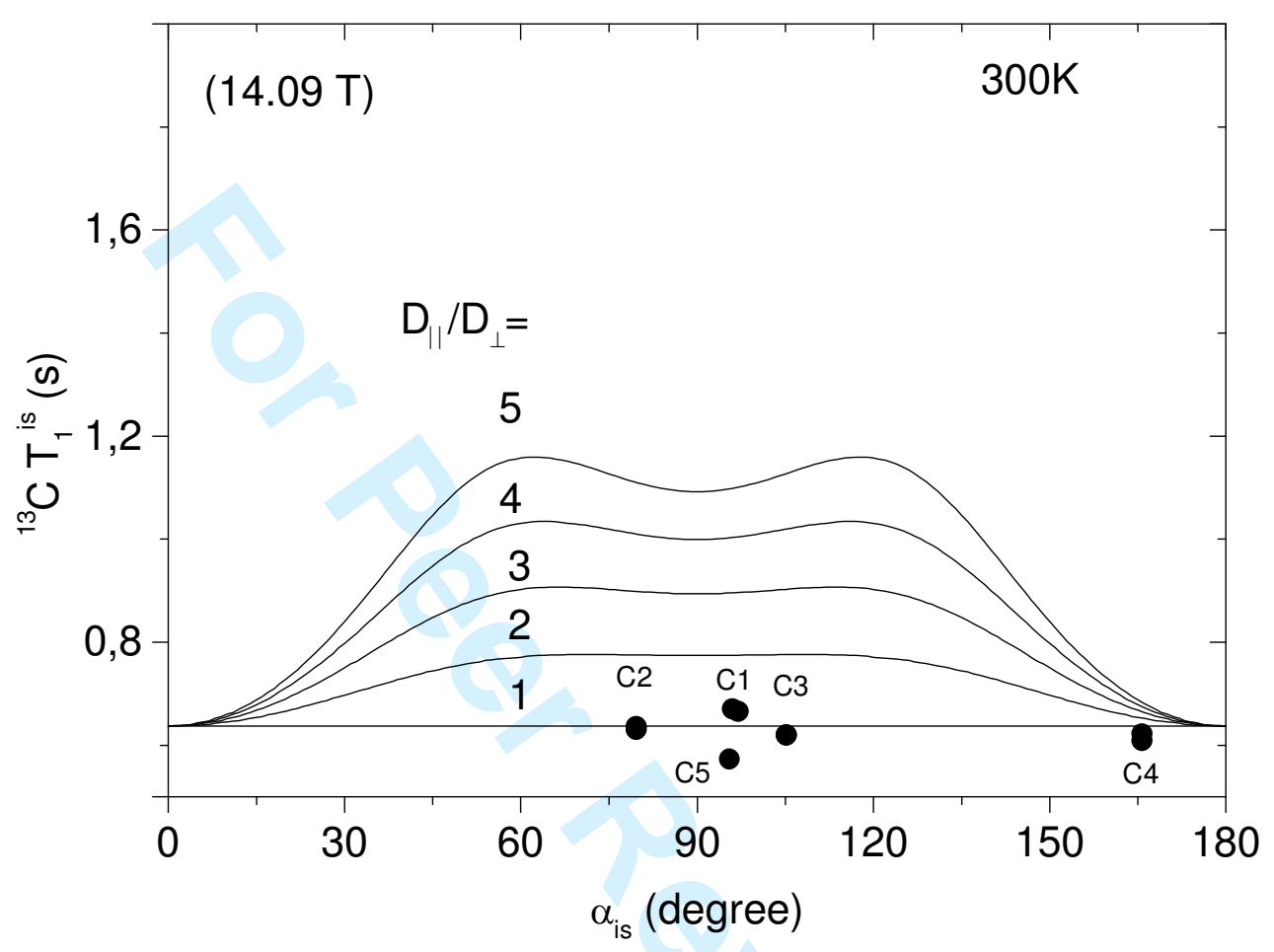

Fig. 5a 


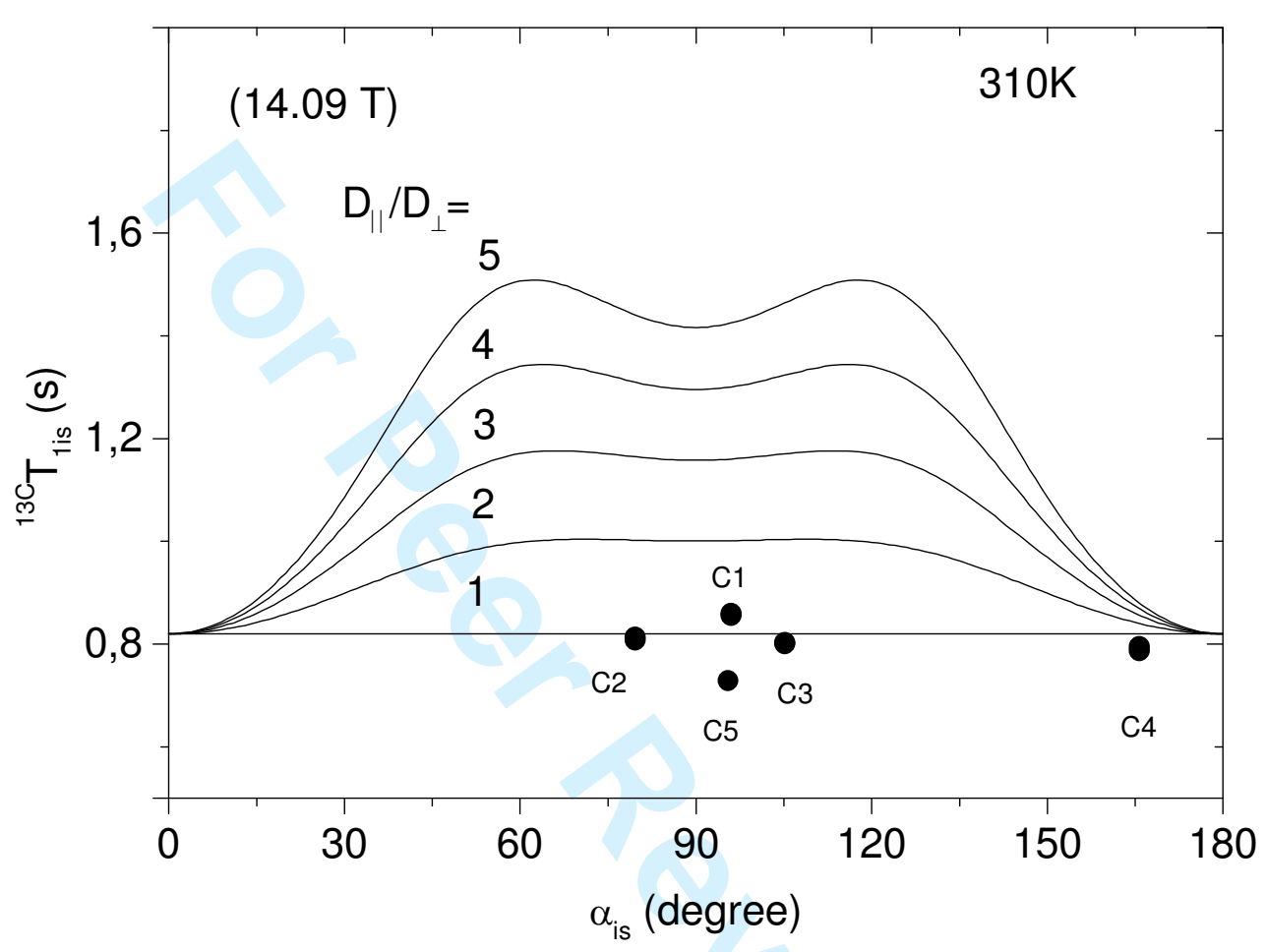

Fig. $5 b$ 


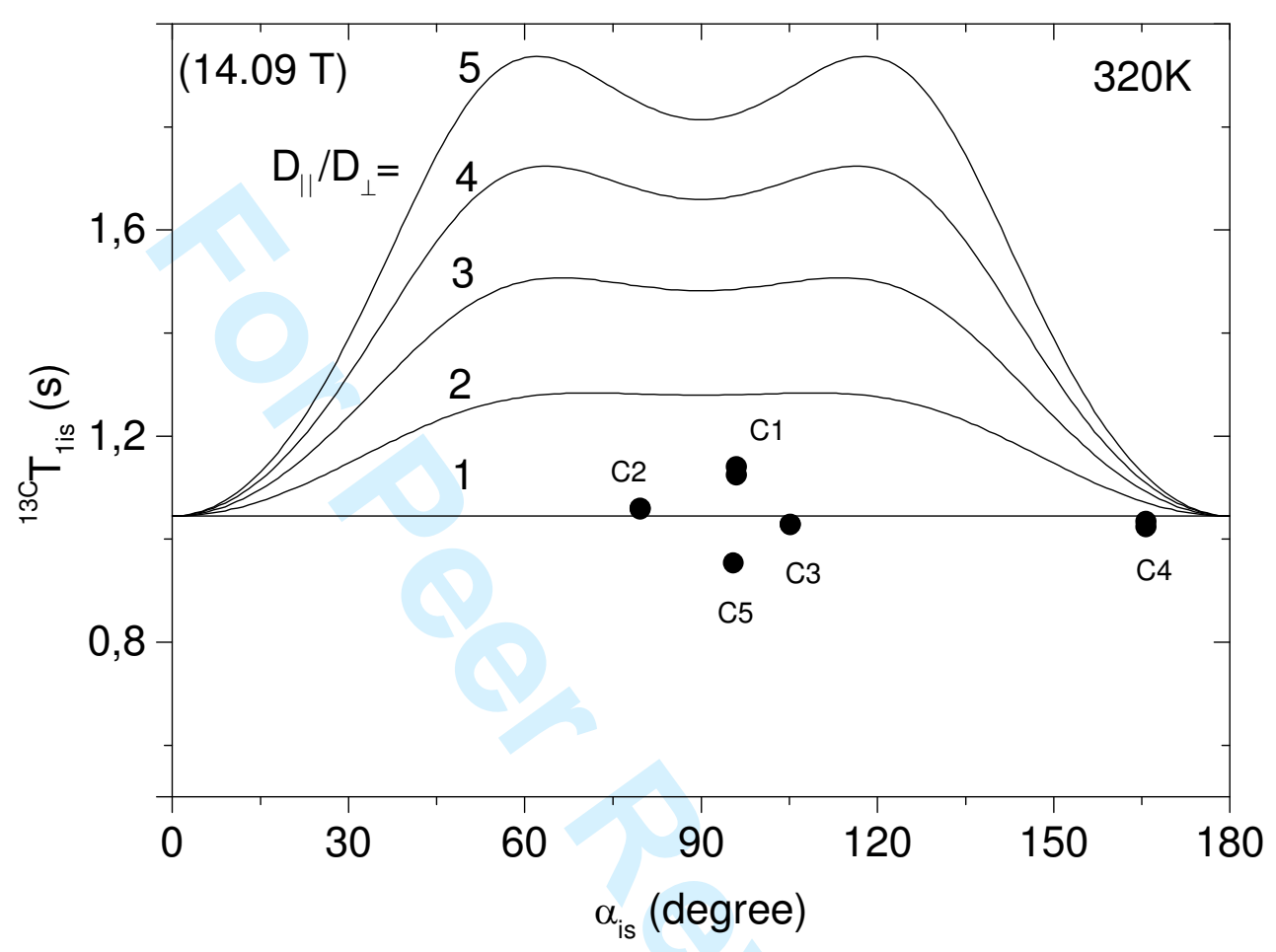

Fig. 5c 


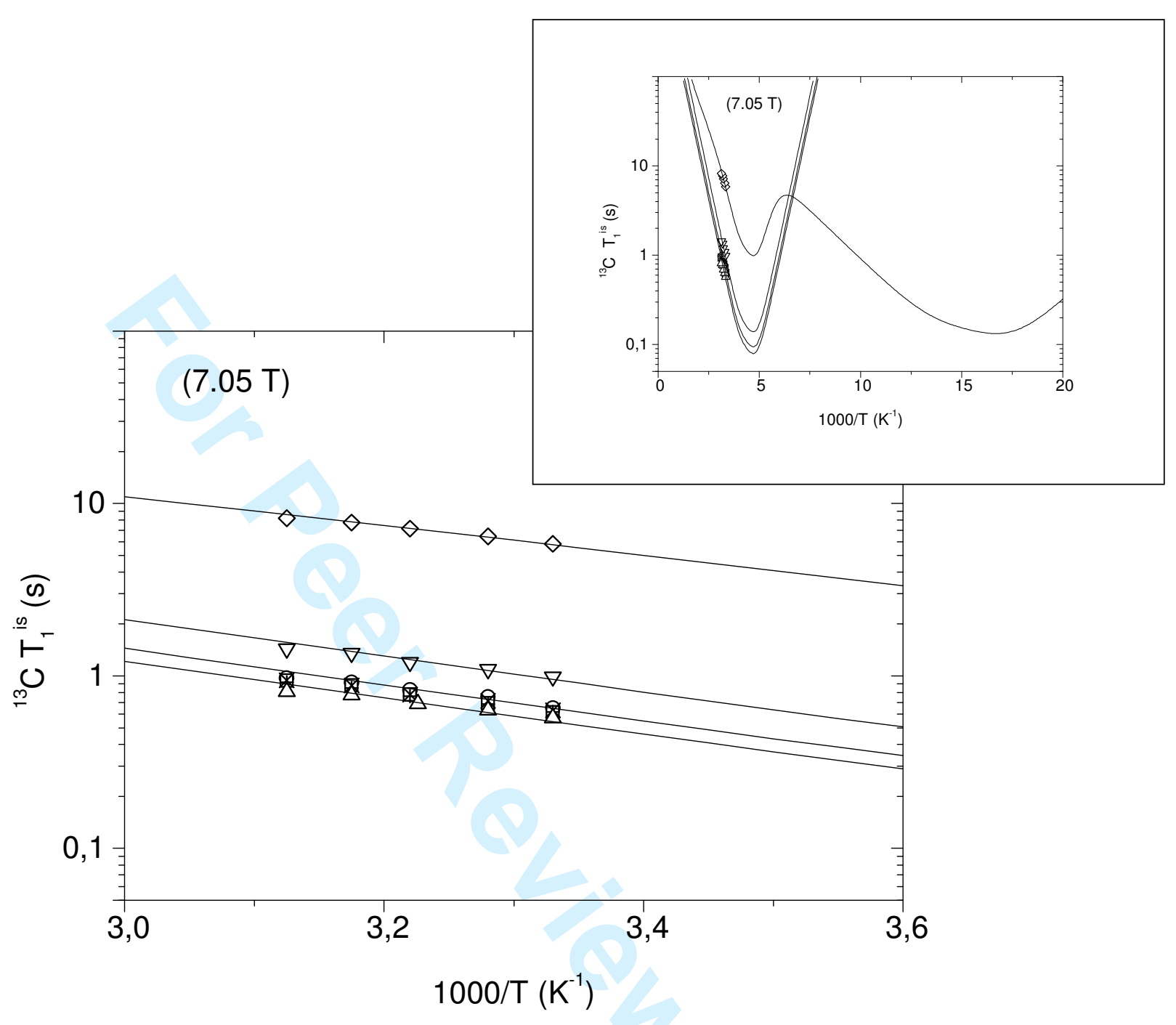

Fig. 6a 


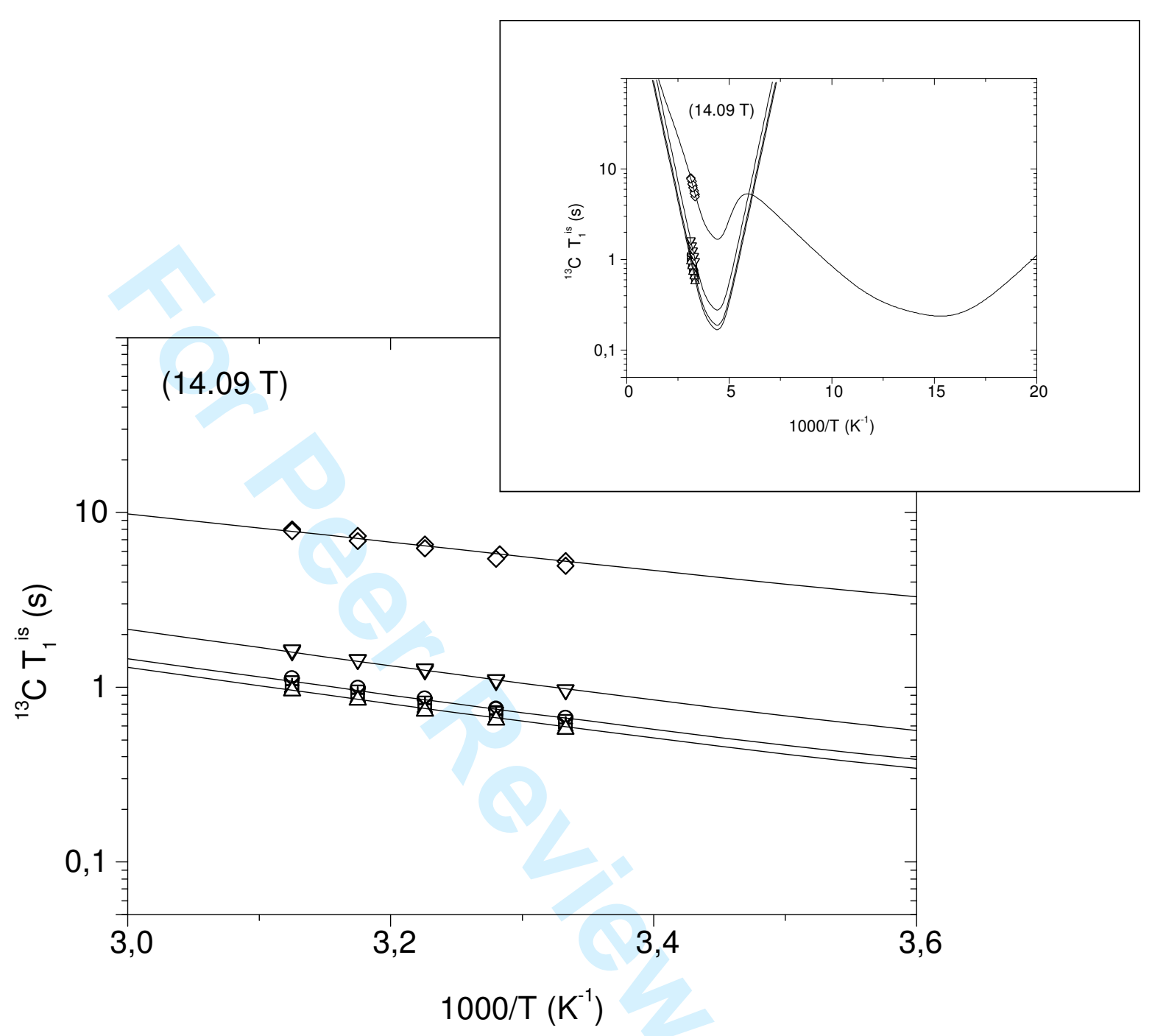

Fig. 6b 


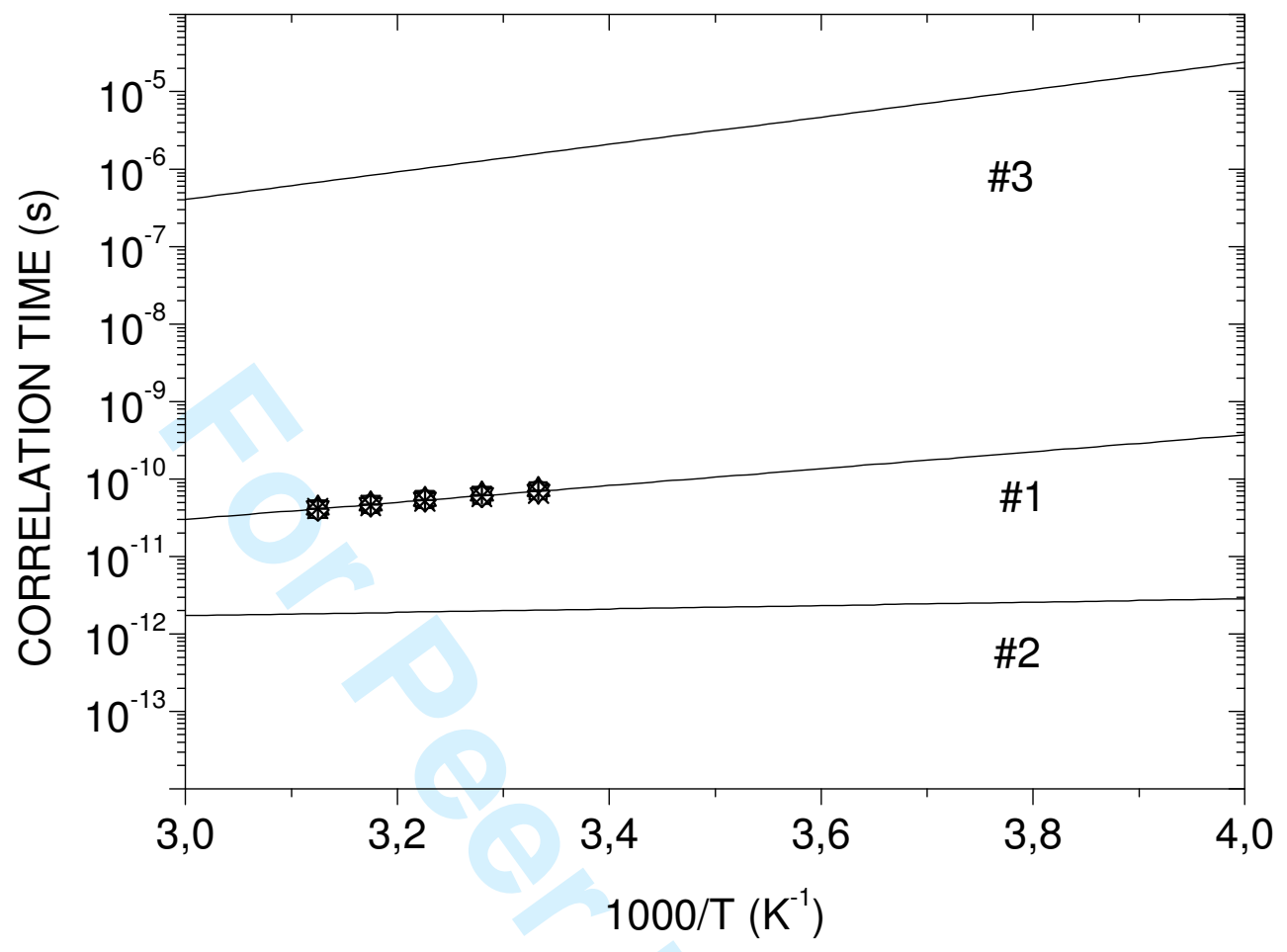

Fig. 7 


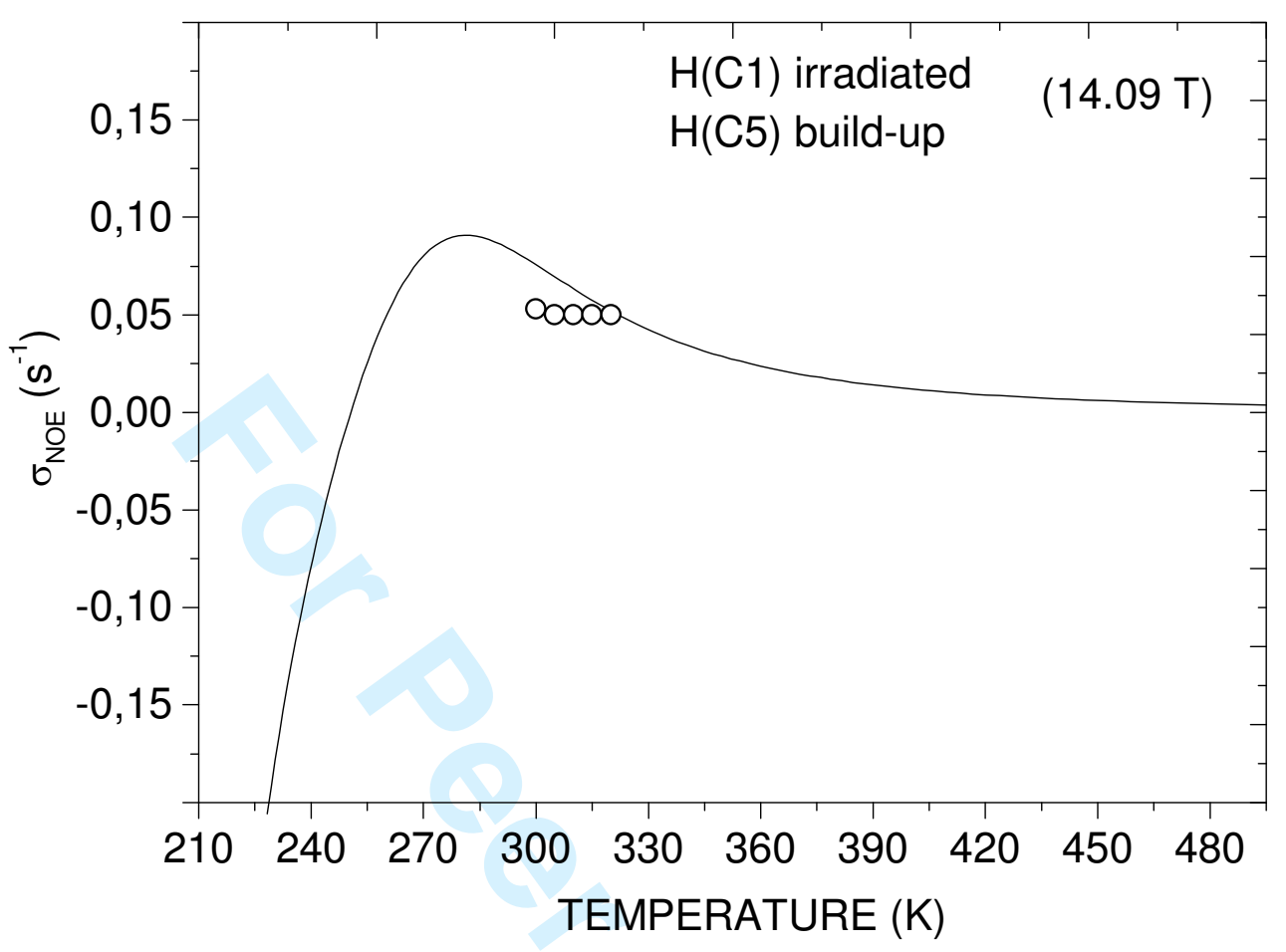

Fig. 8a 


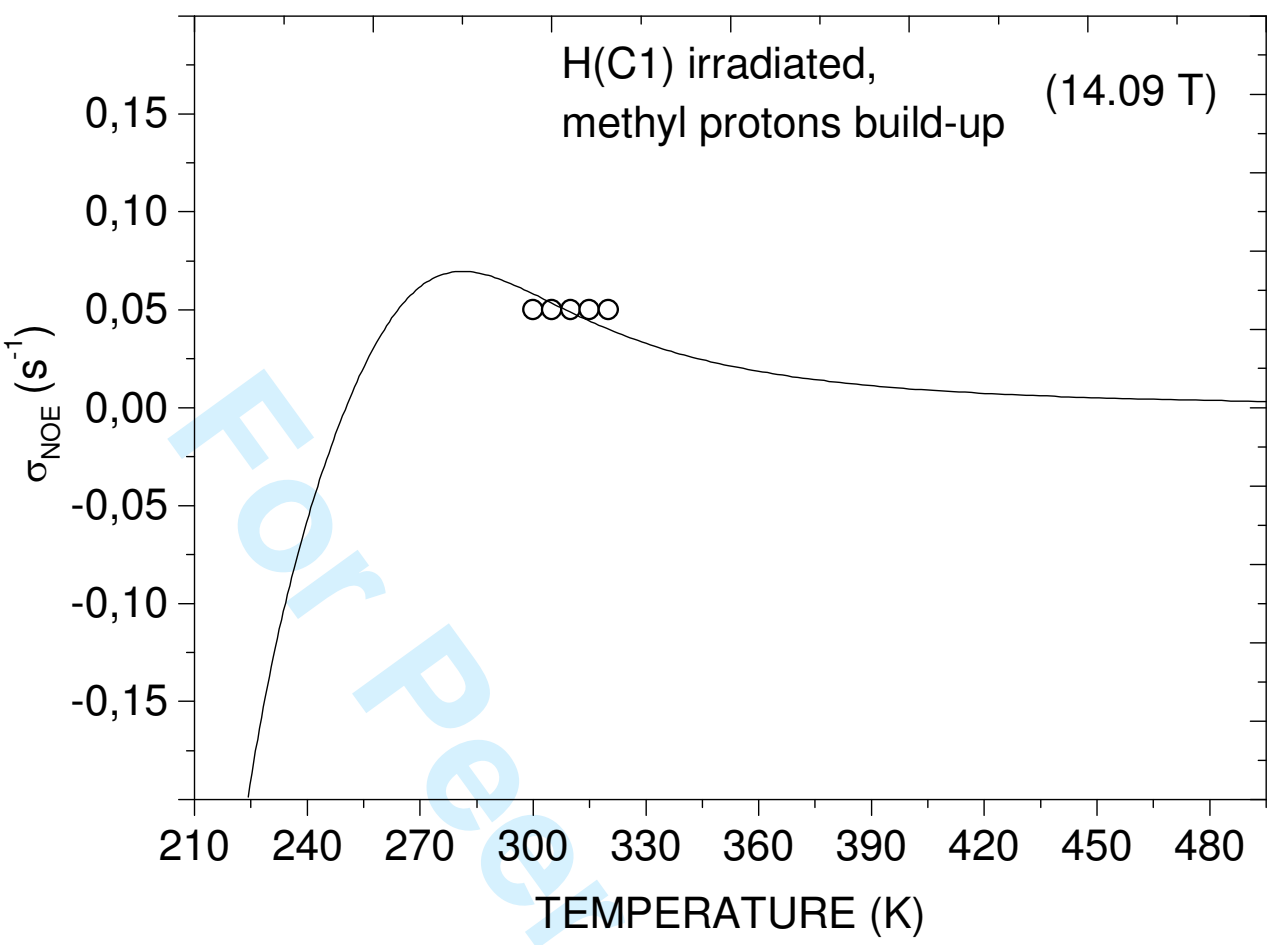

Fig. 8b 